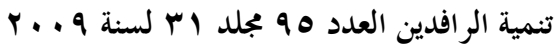

$$
\begin{aligned}
& \text { كلية الإدارة والاقتصاد -جامعة الموصل } \\
& \text { ص ص[1.9-10] } \\
& \text { حدود ومسؤولية مدقث الحسابات عن مدى الثقة الماتة }
\end{aligned}
$$

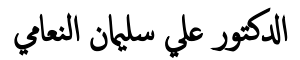

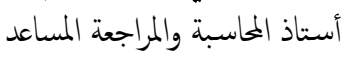

$$
\begin{aligned}
& \text { كلية الاقتصاد والعلوم الإدارية-جامعة الأزهر }
\end{aligned}
$$

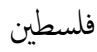

\footnotetext{
المستخلص

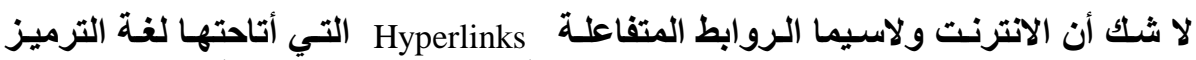

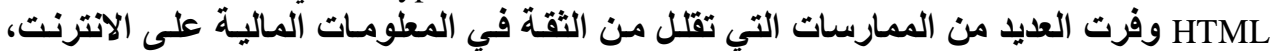

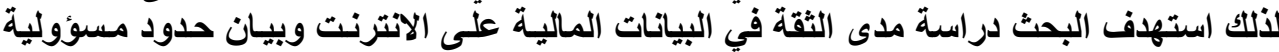

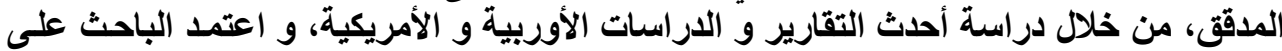

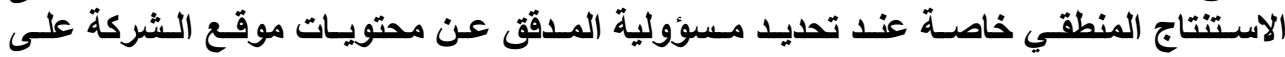

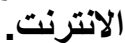

وبيّن الباحث أهم الممارسـات التي تحد من مصداقية المعلومسات المالية على الانترنت،

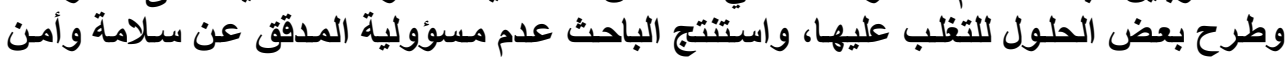

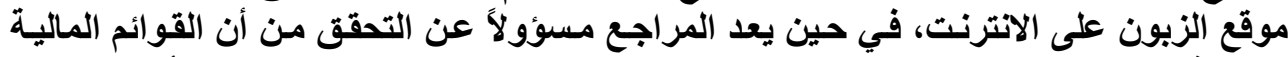

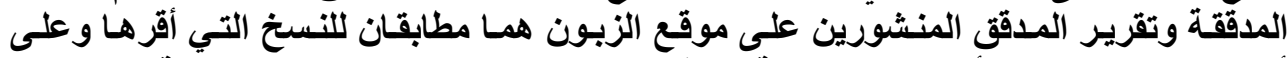

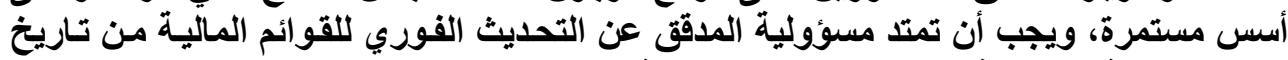

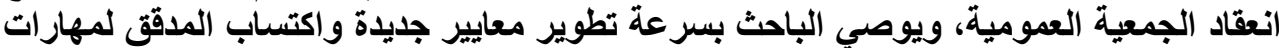

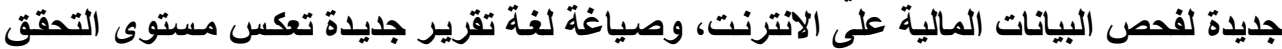
ومقار المسؤولية التي يتحملها المدقة على الاتئ.
}

\title{
Auditor's Liability Limits on Financial Information Credibility on Internet
}

Ali S. Al-Nuami (PhD)

Assistant professor of Accounting and Auditing

Al-Azhar University - Palestine

\section{Abstract}

The hyperlinks of HTML of Internet have certainly facilitated several practices that may reduce credibility of financial data on net. Thus, the current study aimed at discussing

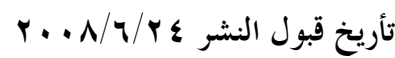

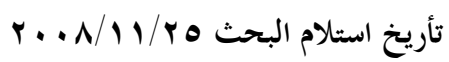




\section{الدكتور النعامي [^^]}

the degree of financial data credibility on net and to show the liability limits of auditor. This has been done via studying one of the modern European and American reports. The researcher tackled he logical conclusion in determining the auditor liability on data of company's website. The researched showed the most essential practices that may limit the creditability of financial data on net as well. Some solutions have been proposed to over come such practices. The researcher referred in conclusion that there is non - liability of auditor of securing the customer's website. While the reviser may be considered as the liable for revising the financial lists and auditor's report released on customer's website. These can be true certified by the reviser himself. The auditor liability should specify the immediate updating to the financial lists due to the meeting of general assembly. The researcher recommends the rapid developing the skills of audition and liability.

المقدمة

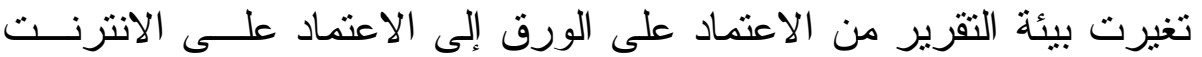

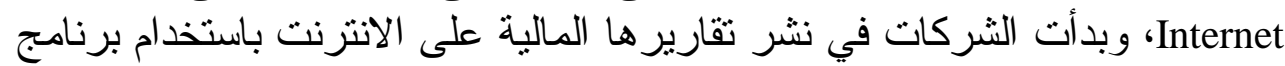
. A dope Acrobat

إذ يقوم هذا البرنامج بحفظ الإطار الكامل للقو ائم المالية من دون وجـــود أي

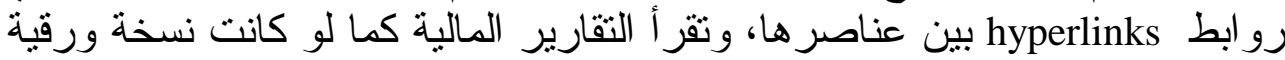

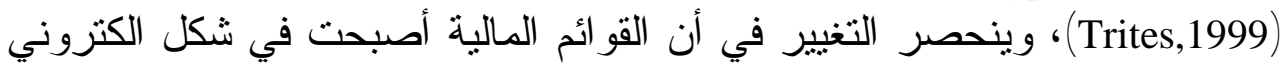

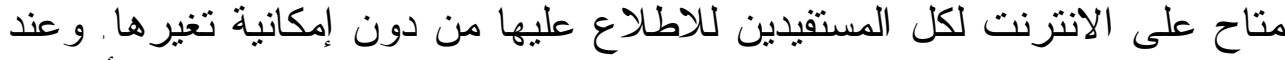
هذا المستوى من التكنولوجيا لم يشكل نشر المعلومات المالية على الانترنت أنس أي تحد

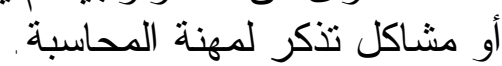

ومع ظهور الثبكة الدولية للمعلومات (الويب) The World Wide Web ولغة

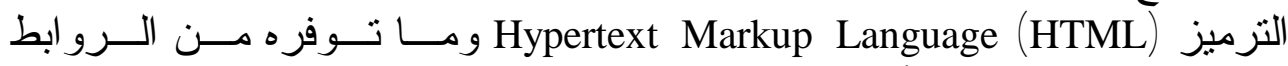

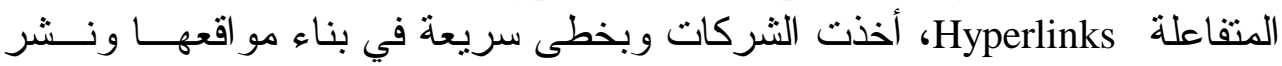
تقارير ها المالية على الانترنت باستخدام هذه اللغة.

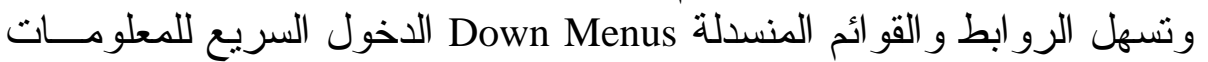

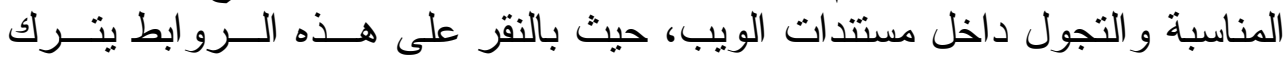

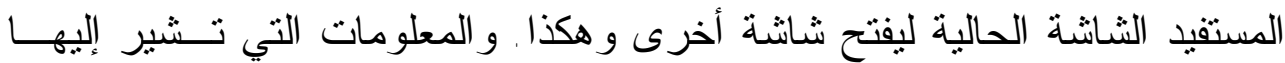

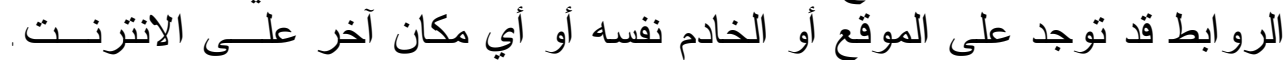

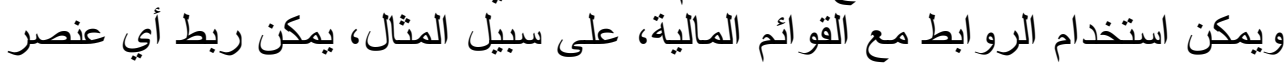

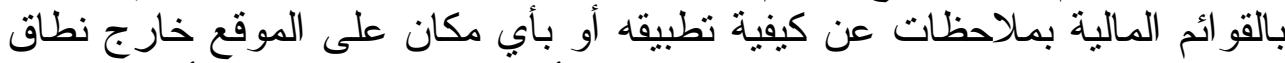

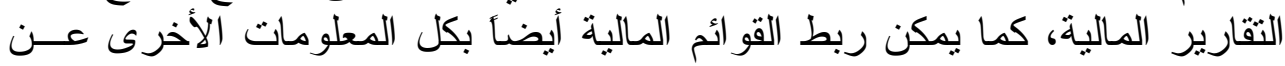

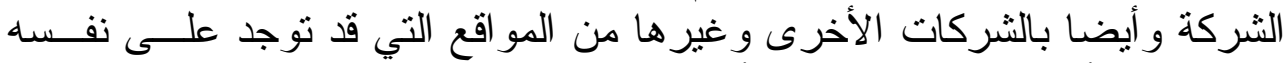
الخادم نفسه أو خادم آخر في دولة أخرى (Lymr \& Others, 1999) .

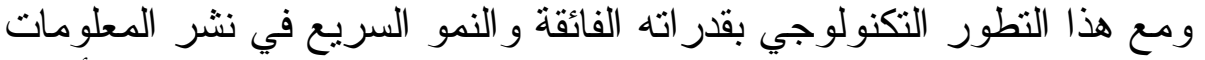

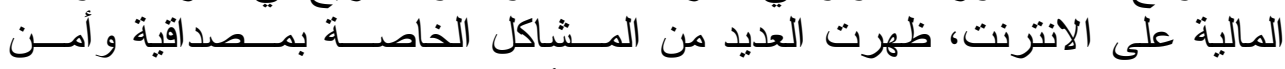
المعلومات المالية على الانتزنت التيرنت نذكر منها ما بأني : 


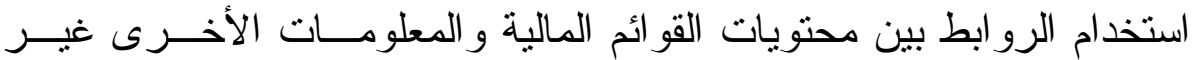

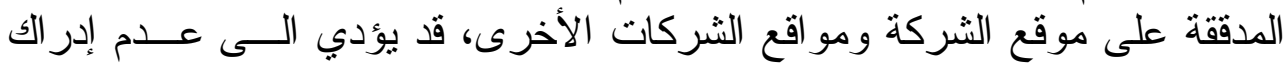

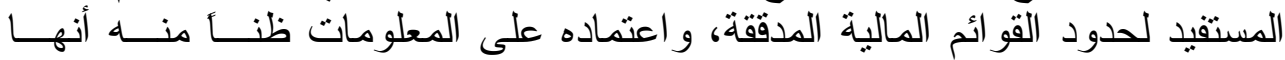

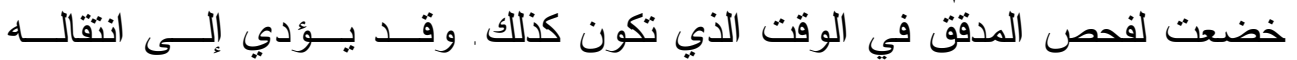

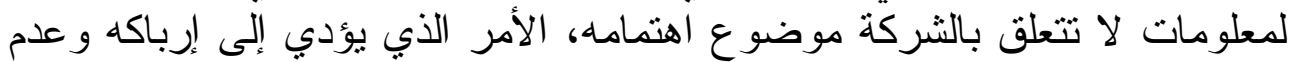

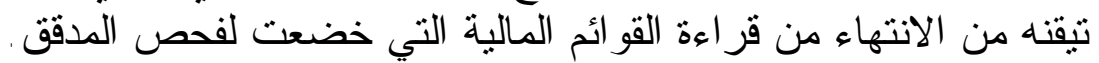

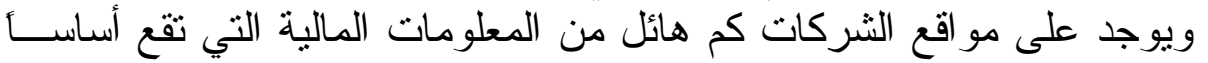

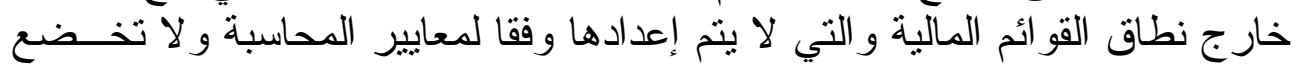

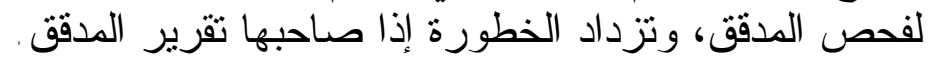

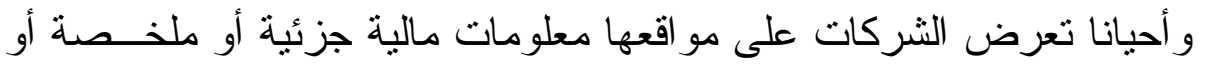

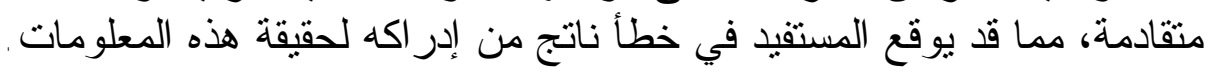

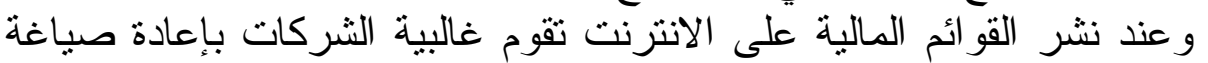

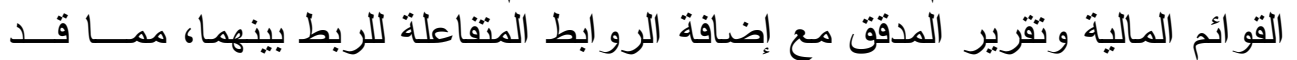

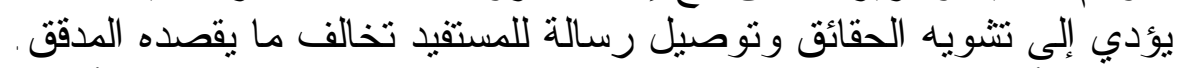

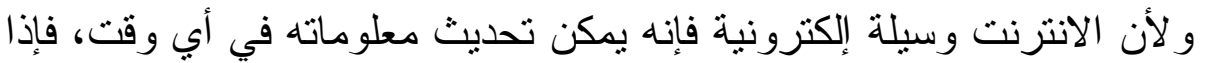

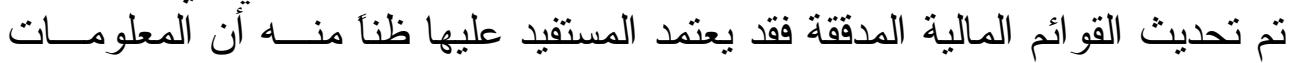

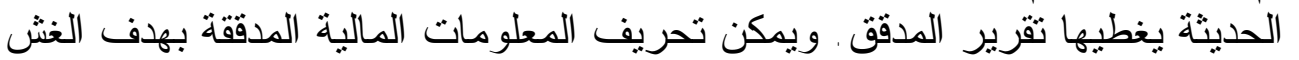

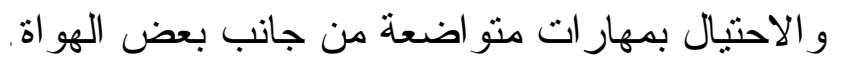

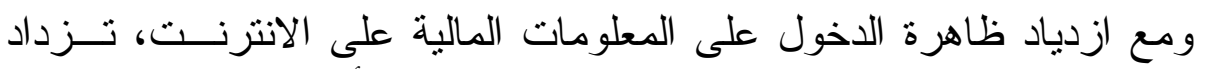

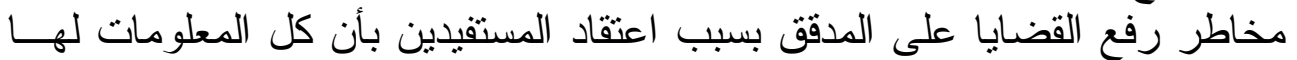

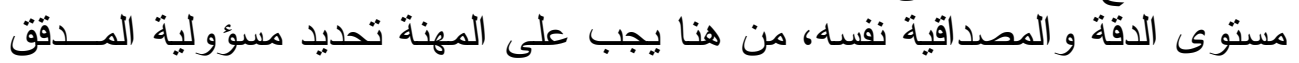

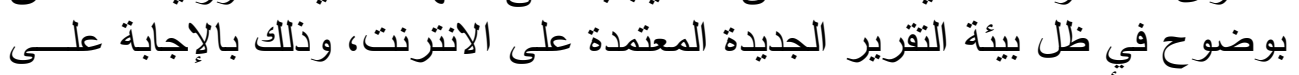

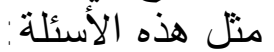

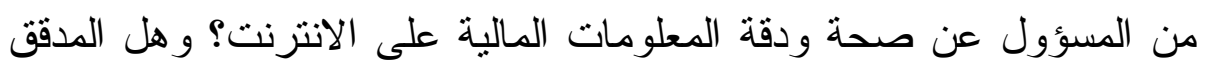

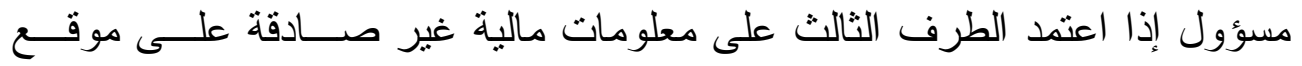

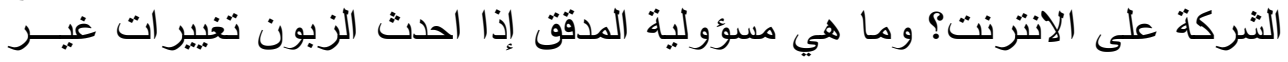

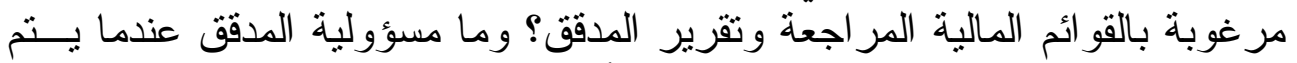

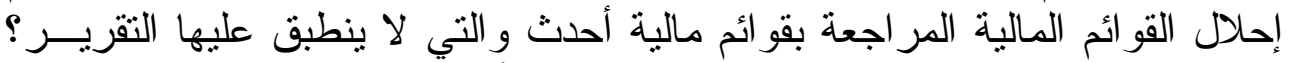

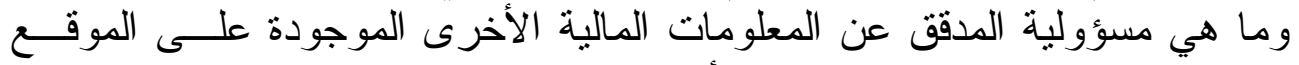

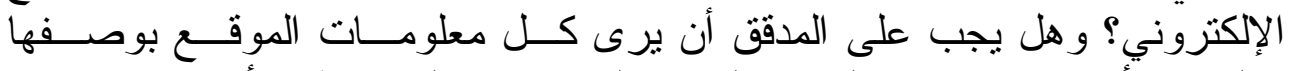

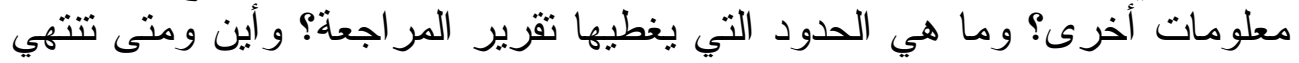

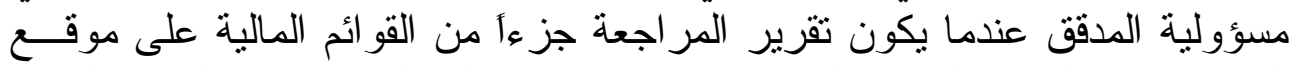

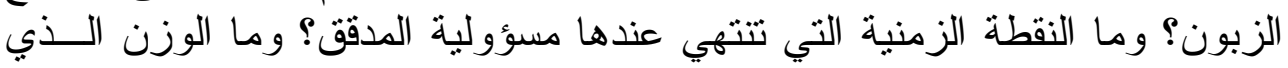

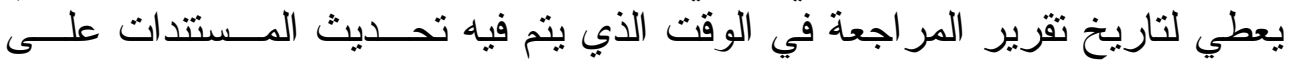

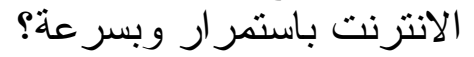




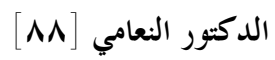

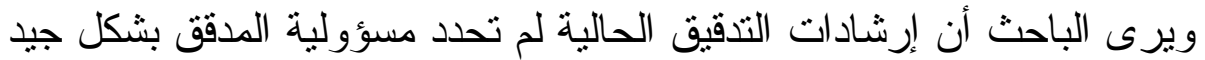

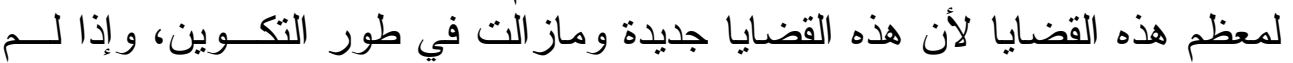

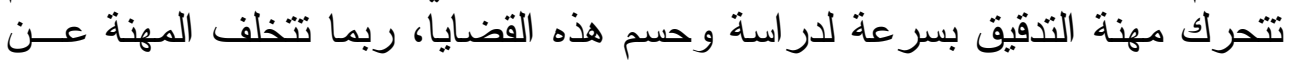

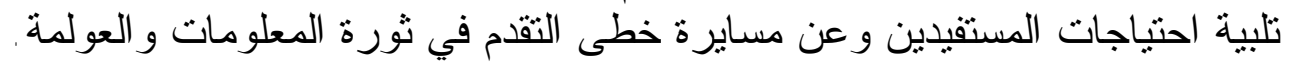

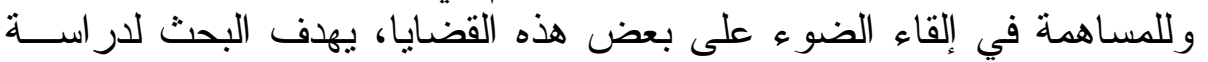

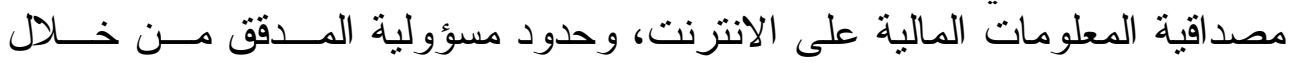
الإجابة على الأسئلة الآتية: الإلية • إلى أي حد تستخدم الانترنت وسيلة لنشر المعلومات المالية، مع الإثــارة لبيئــة

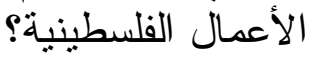

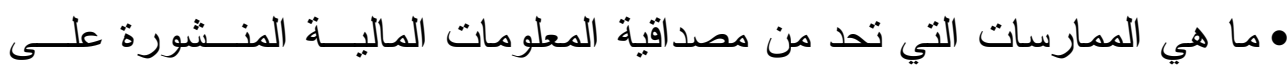

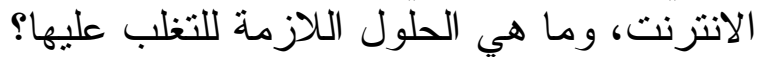

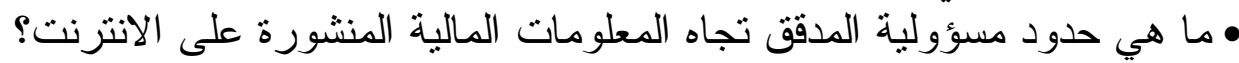

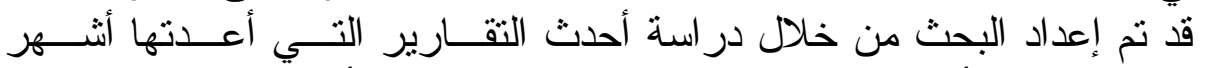

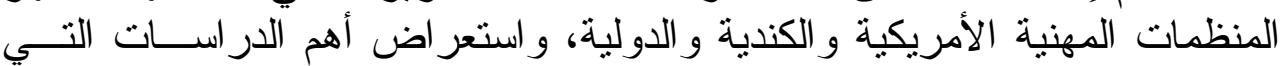

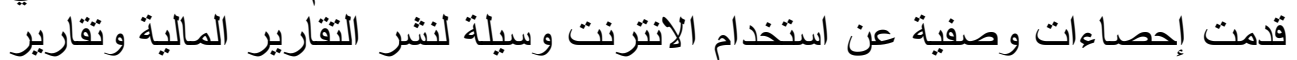

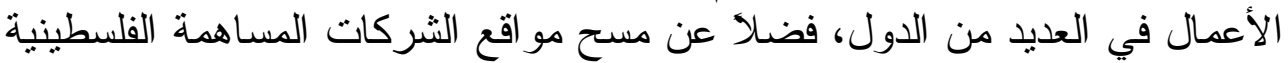

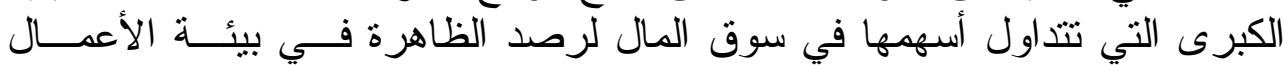

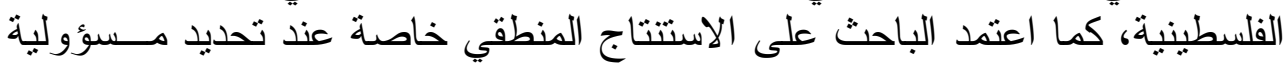

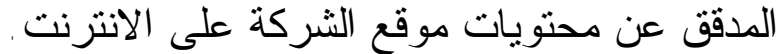

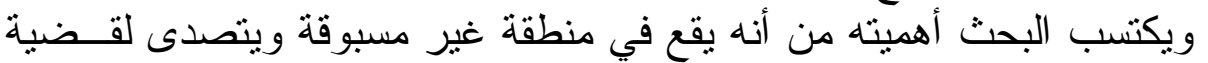

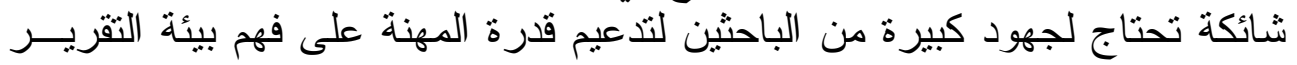

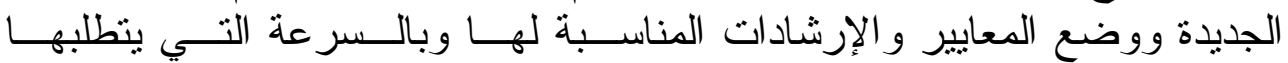

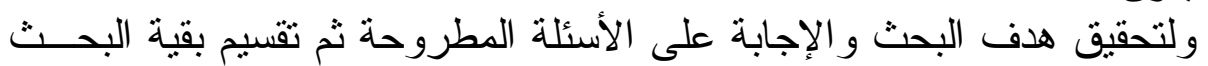

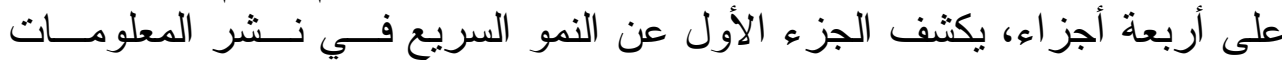

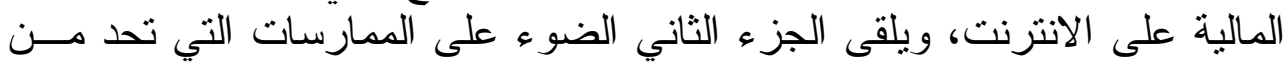

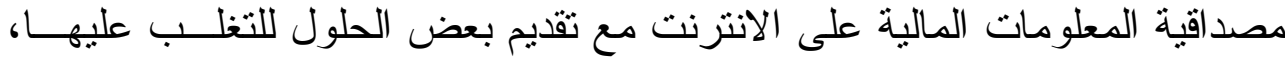

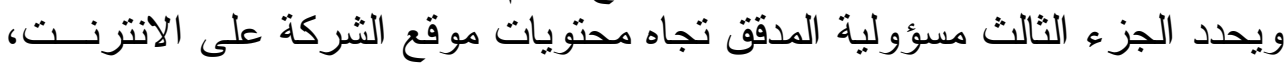

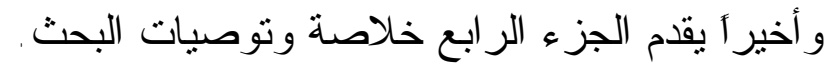

\section{أولاً - نشر المعلومات المالية على الاتترنت}

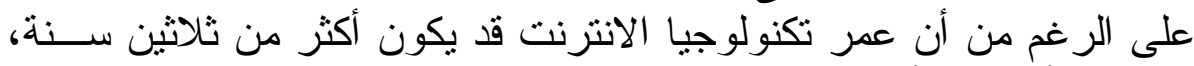

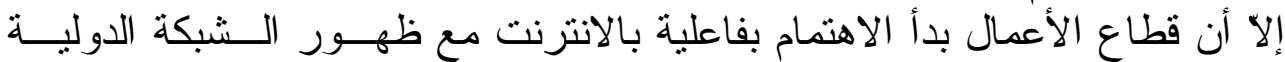

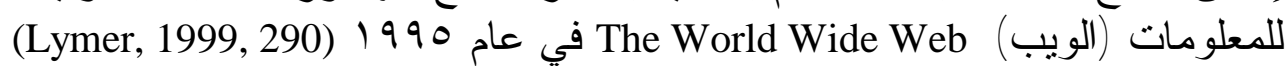

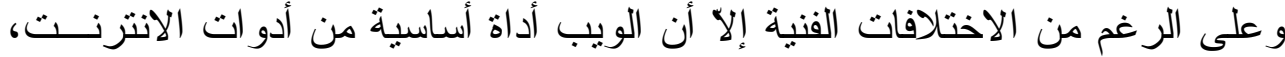

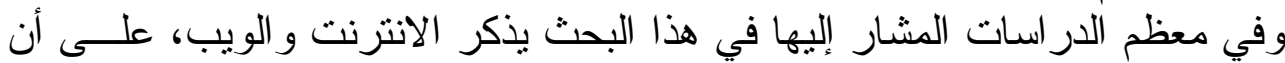


كل منهما مر ادف للآخر ، وفي هذا البحث نستخدم كلمة الانترنت للالالة علـى أي

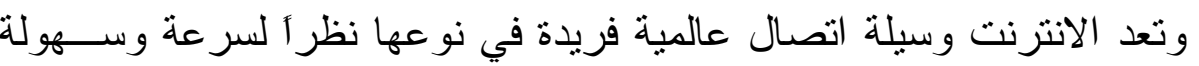

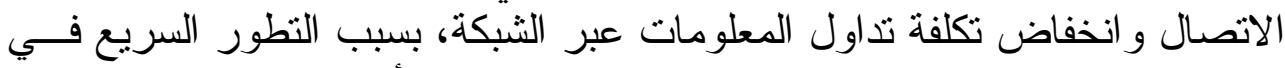

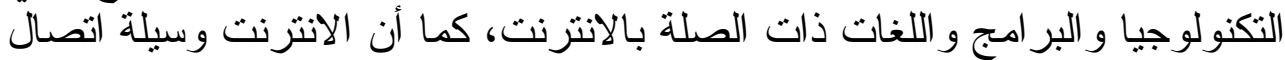

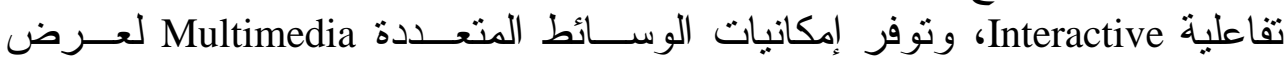

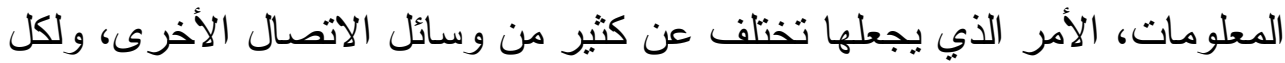

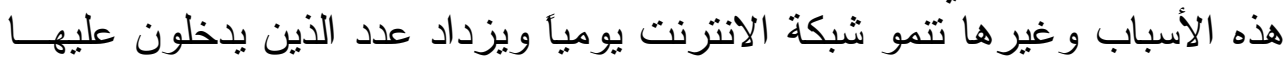

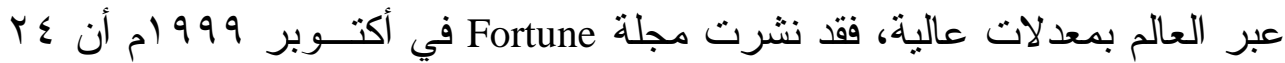

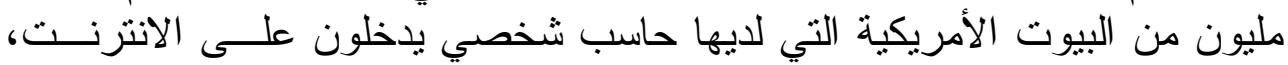

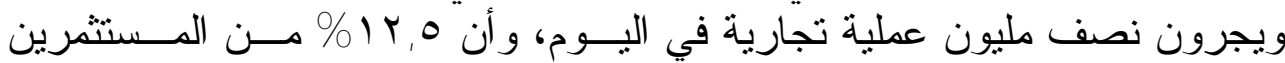

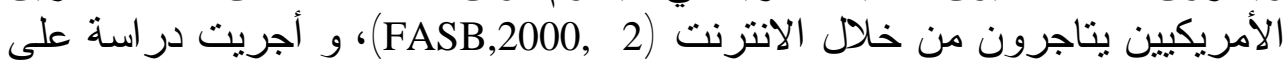

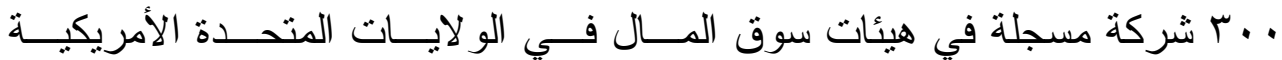

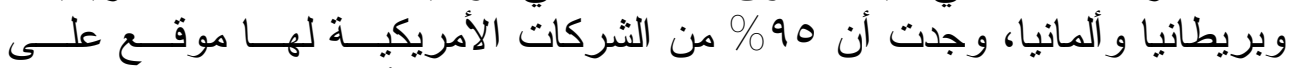

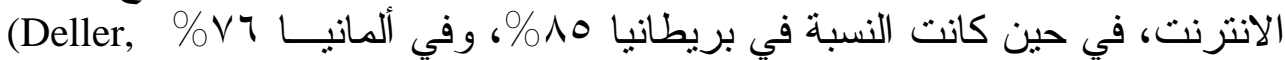
Stubenrath, \& Weber, 1999)

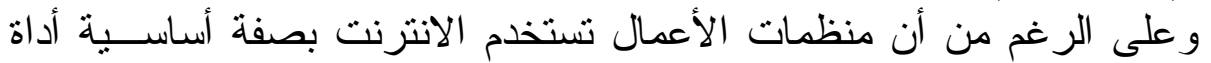

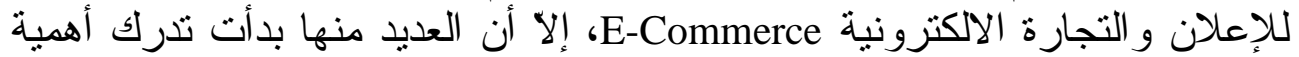

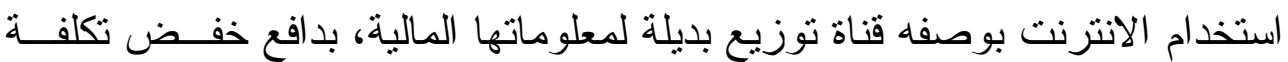

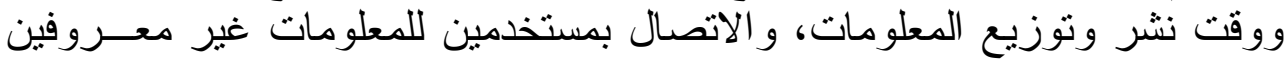

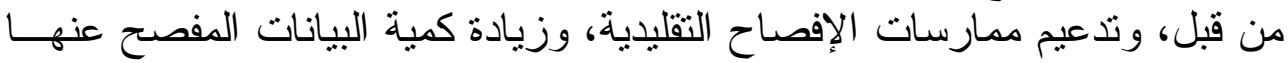

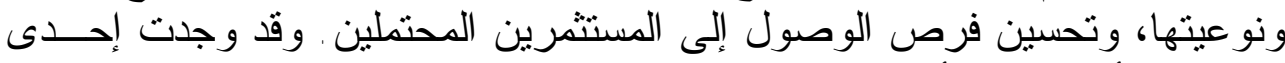

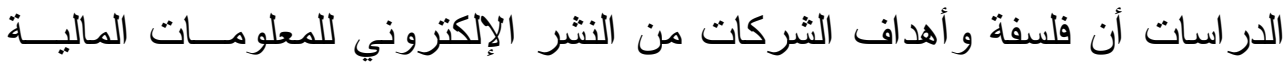

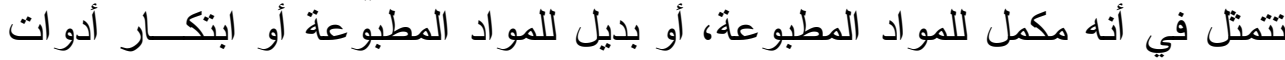

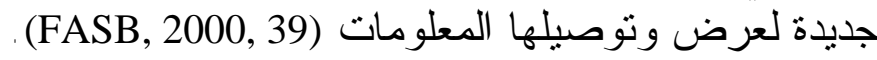
وتعرض الثركات المعلومات المالية غالباً على جزء هُ منفصل بمو اقعها يسهل

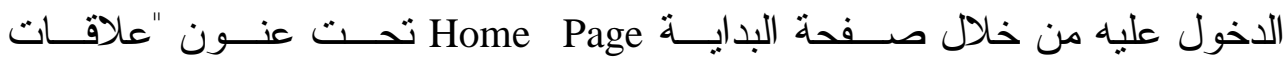

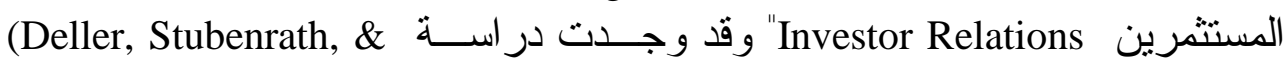

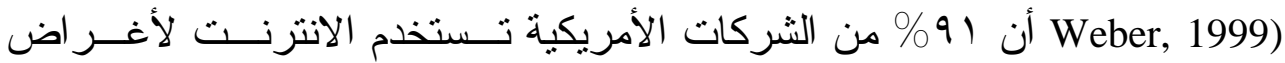

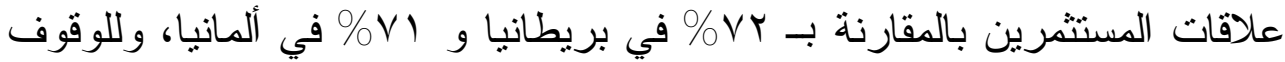

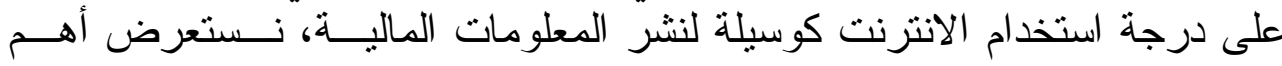
الدراسات السابقة في العديد من الدول. 


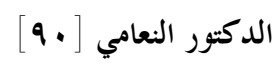

الار اسات ه V V السابقة

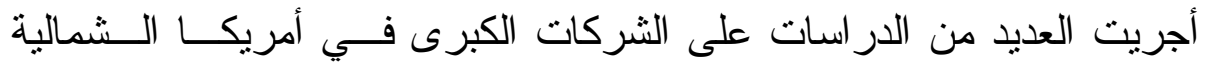

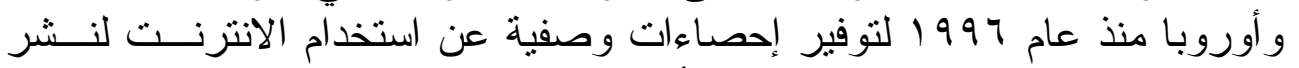

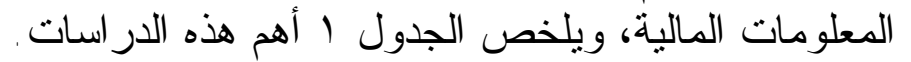

\begin{tabular}{|c|c|c|c|c|c|c|}
\hline \multicolumn{7}{|c|}{ ملخص بالأدراسات السابقة } \\
\hline ملمالية جزئئية المئية & ملمالية كامليهات & مالتي عليهات & التي لهات & الثركات & الدولة الد & الدر اسة \\
\hline$\%$ rr & $\%$ \% & $\% \circ \varepsilon$ & $\% 97$ & 10. & الو لاياتة & $\begin{array}{l}\text { Ptervick \& Gillet, } \\
1996\end{array}$ \\
\hline$\% r r$ & $\%$ \% & $\% \curlyvee \wedge$ & $\% 9 \wedge$ & o. & المتحدة الايات & $\begin{array}{l}\text { Gray \& } \\
\text { Debreeceny,1997 }\end{array}$ \\
\hline$\% r v$ & $\% r \varepsilon$ & $\% \times 1$ & $\% 97$ & $1 \ldots$ & الو لاياتة & $\begin{array}{l}\text { Debreceny, } \\
\text { Gray,\&Barry } 1998\end{array}$ \\
\hline \%rт & $\% ч$. & $\% \wedge 4$ & $\% \wedge \vee$ & rq. & المتحدة اللات & $\begin{array}{l}\text { Ashbaugh, } \\
\text { Johnstone, } \\
\text { \&Warfied, } 1999\end{array}$ \\
\hline \% & $\% ч$. & $\%$ q & $\% 99$ & $1 \ldots$ & الو الاياتة & FASB, 2000. \\
\hline$\%$ \% & $\%$ ro & $\% 01$ & $\% \vee$. & $r v \cdot$ & أمريكا & Trites, 1999 \\
\hline$\%$ & $\%$ or & $\% \uparrow \wedge$ & $\% 94$ & 0 . & المملكة & Lymer,1997 \\
\hline$\%$ r & $\% r r$ & $\%$ or & $\% \vee \varepsilon$ & $r .4$ & المتحلكة & $\begin{array}{l}\text { Graven \& } \\
\text { Marston,1999 }\end{array}$ \\
\hline \multirow[t]{4}{*}{$\% \times 1$} & $\% 11$ & $\% \wedge r$ & $\% 9$. & VT & فنلندا & $\begin{array}{l}\text { Lymer \& Tallbery, } \\
1997\end{array}$ \\
\hline & & $\% \wedge r$ & $\% \wedge \vee$ & $r$. & ألمانيا & $\begin{array}{l}\text { Deller, Stubenrath, \& } \\
\text { Weber, } 1999\end{array}$ \\
\hline & & $\% \wedge r$ & $\% 90$ & 7. & السويد & Hedlin ,1999 \\
\hline & & $\% \vee r$ & $\% \wedge \wedge$ & 0 . & والموندانيا & $\begin{array}{l}\text { Debreceny \& Gray, } \\
1999\end{array}$ \\
\hline$\%$ \%V & $\%$ ro & $\% \pi r$ & $\% \wedge 7$ & 77. & ب بدولة & Lymer\&Others, 1999 \\
\hline
\end{tabular}




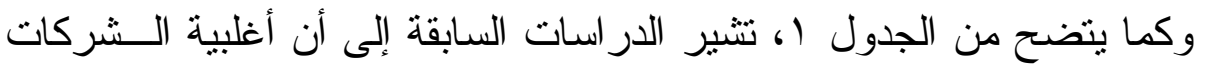

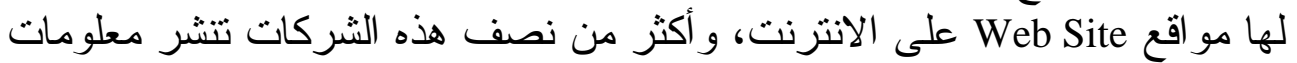

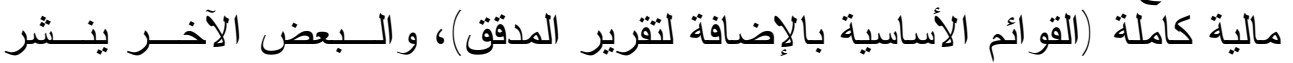

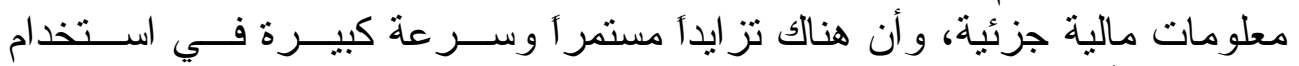

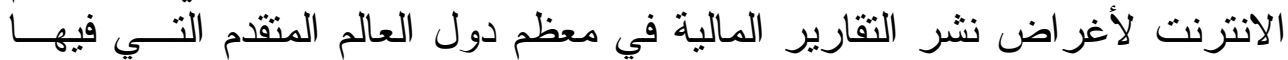

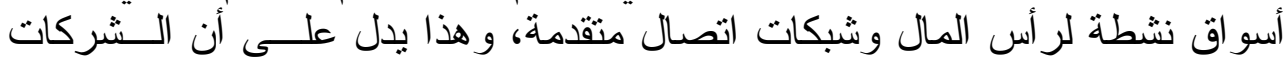

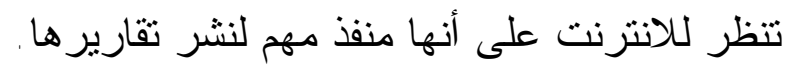

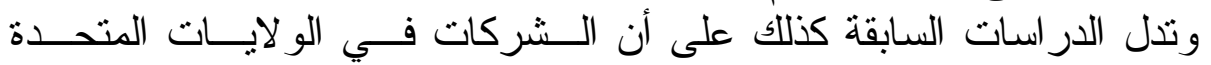

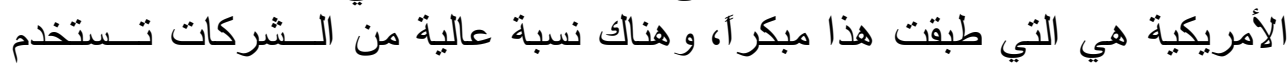

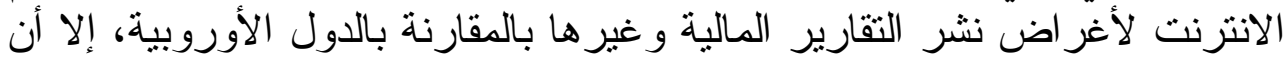

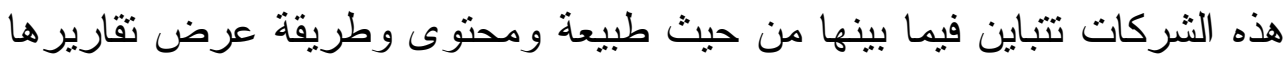

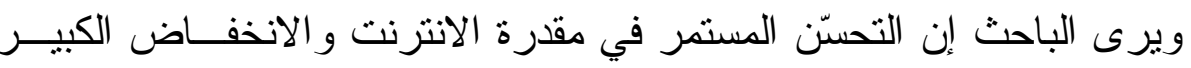
على الانترنت.

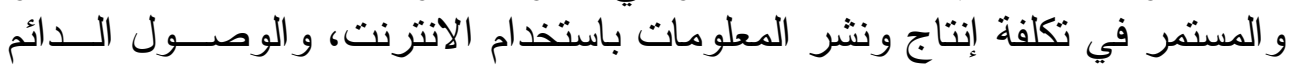

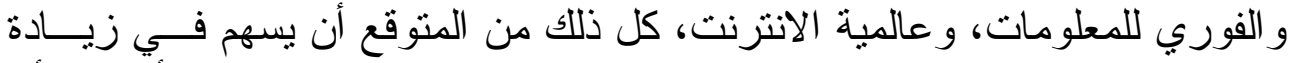

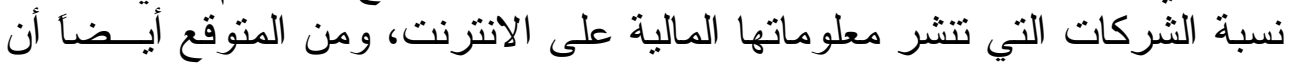

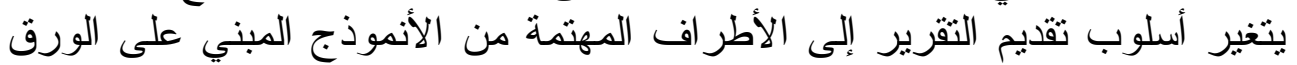

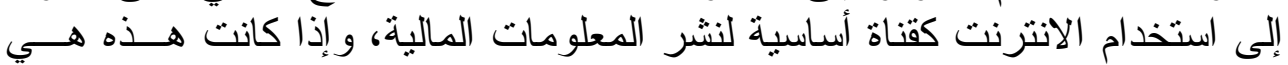
الحال في دول أمريكا الثمالية وأوروبا، فما هو الوضع في فلسطين؟

$$
\text { نشر المعلومات المالية على الاتترنت في فلسطين }
$$

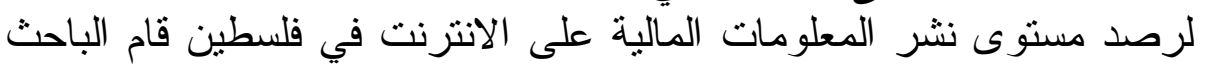

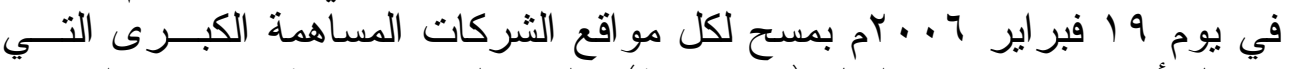

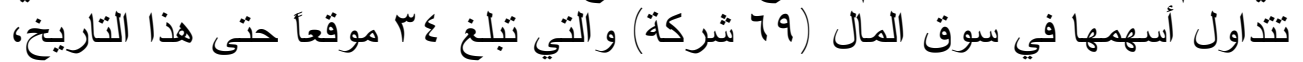

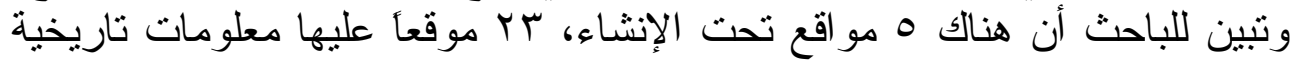

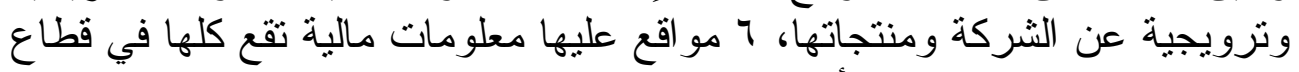

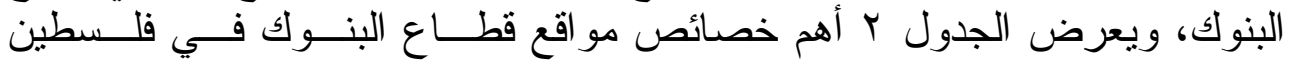




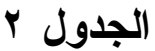

أهم خصائص مواقع قطاع البنوك في فلسطين وخصائصها

\begin{tabular}{|c|c|c|c|c|c|c|}
\hline إمكانية السحب & الروابط & تقريز & السنة & مالية أخرى معات & قالية & اسم البنك \\
\hline نعم & نعم & نعم & 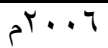 & نعم & نعم & فلسطين المحدود \\
\hline ن نعم & نعم & ن ن نمم & $r \ldots r$ & نعم & نعم & العربي المحدود \\
\hline نعم & نعم & نعم & $r \ldots r$ & نعم & نعم & القاهرة عمان \\
\hline نعم & نعم & نعم & $r \ldots r$ & نعم & نعم & الأردن \\
\hline نعم & نعم & نعم & $r \ldots r$ & نعم & نعم & الإسكان \\
\hline نعم & نعم & نعم & $r \ldots r$ & نعم & نعم & الاستثمار \\
\hline نعم & نعم & ن عم & $r \ldots r$ & نعم & نعم & الإسلامي الفلسطيني \\
\hline نعم & نعم & نعم & $r \ldots r$ & نعم & نعم & الإسلامي العربي \\
\hline
\end{tabular}

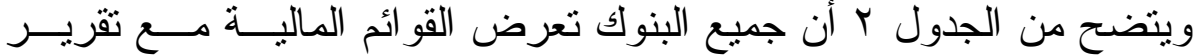

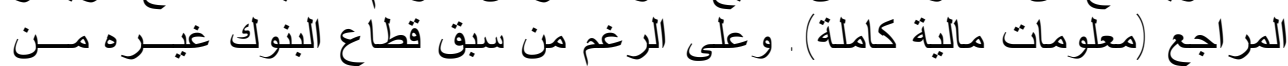

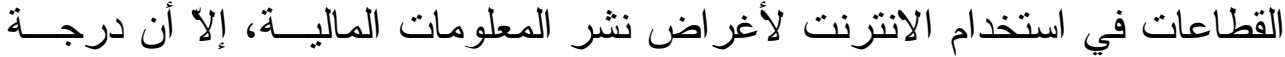

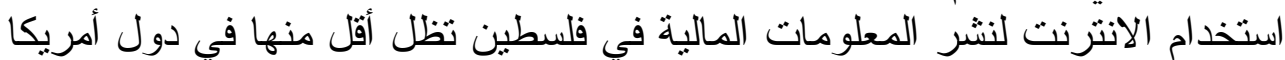

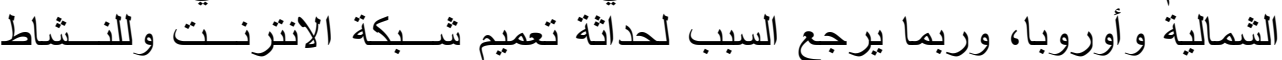
المنو اضع لسوق المال في فلسطين.

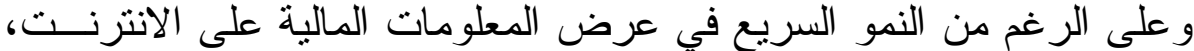
إلا أن نمو الطلب على هذه المعلومات ينوقف على على مصداقيتها.

\section{ثانياً - مصداقية المعلومات المالية على الاتترنت}

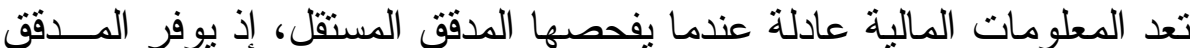

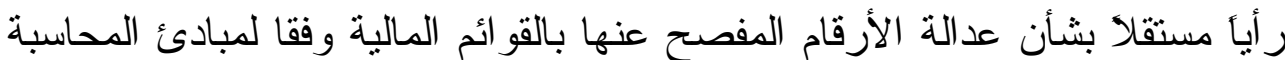

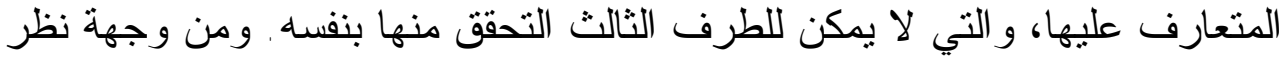

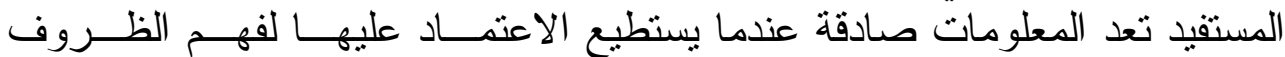

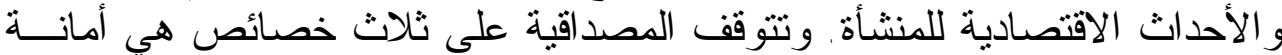

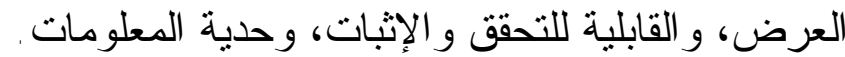

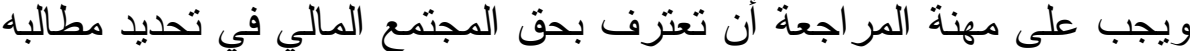

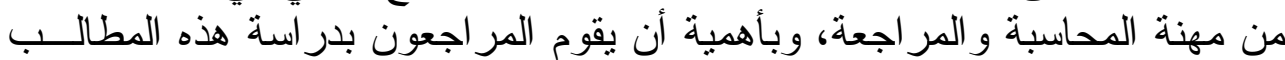

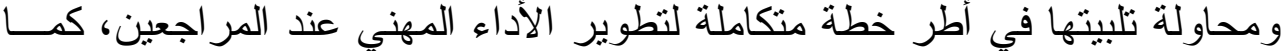

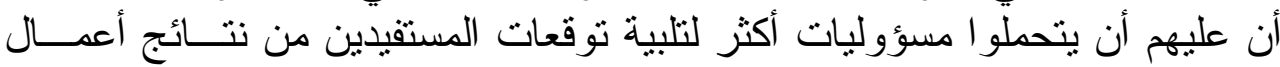

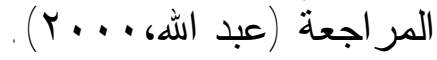




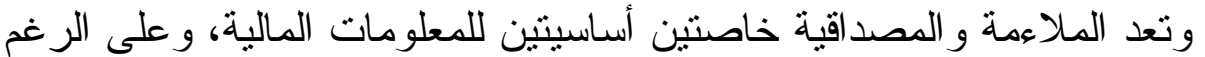

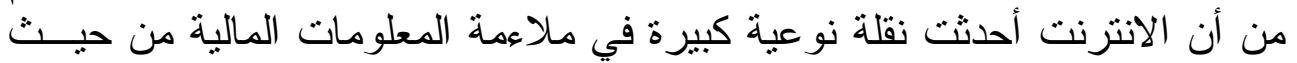

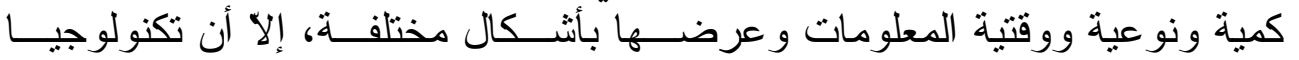
الانتزنت أتاحت العديد من الممارسات التي أثرت على مصداقية المعلومات المالية

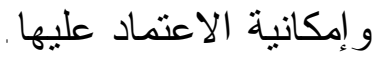

\section{الممارسات التي أثرت على المصداقية}

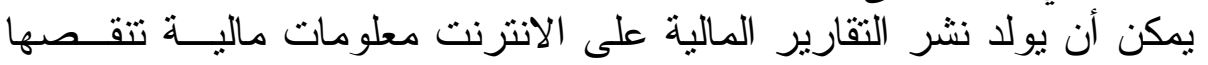

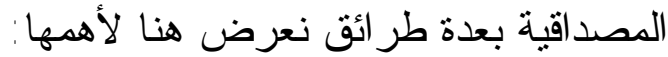

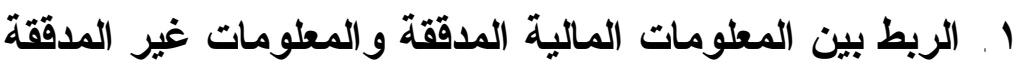

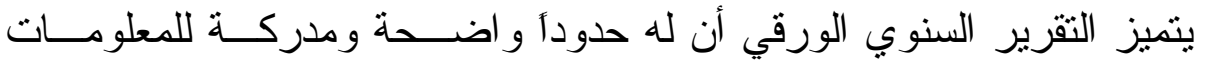

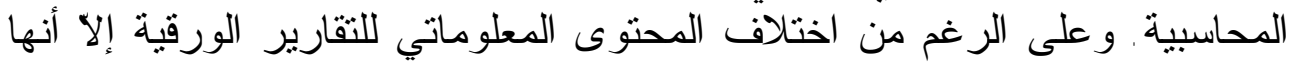

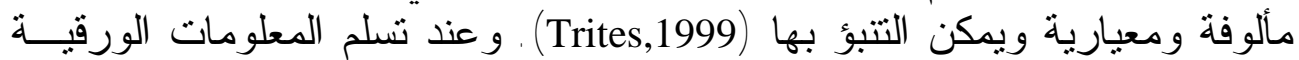

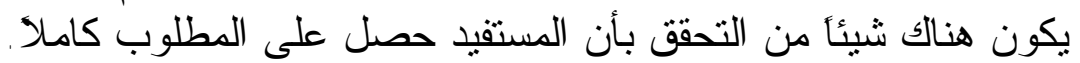

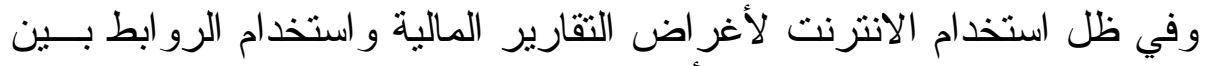

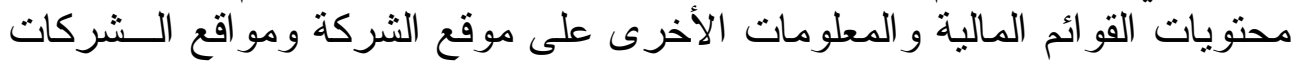

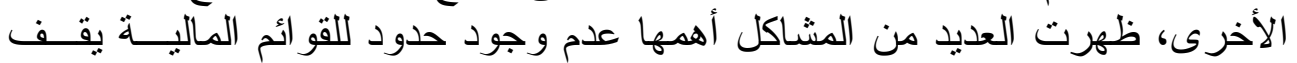

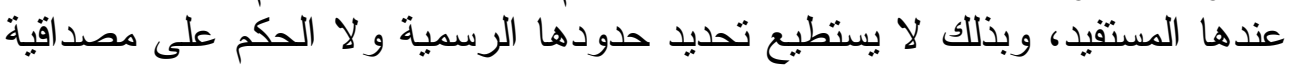

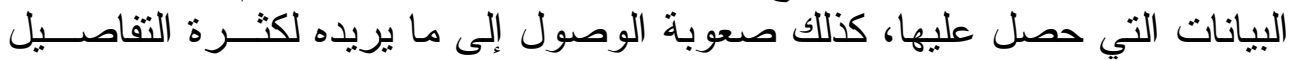

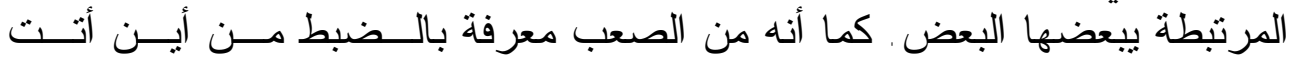

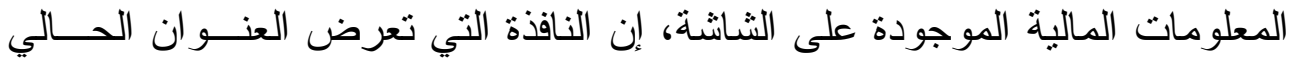

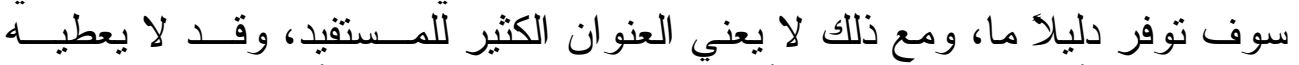

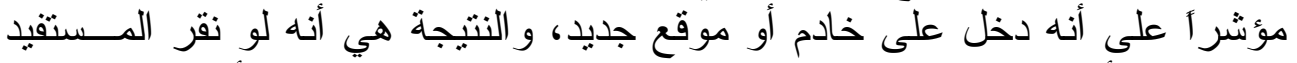

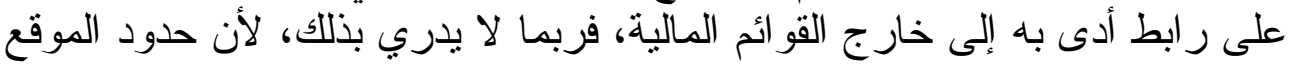

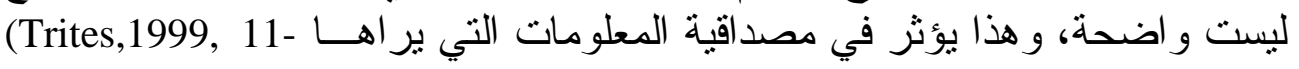

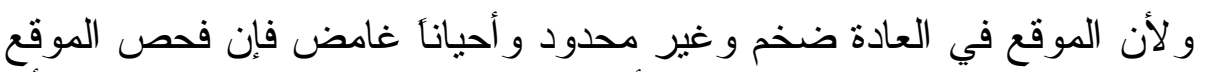

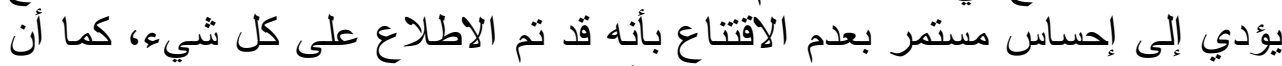

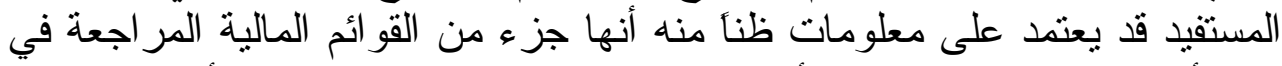

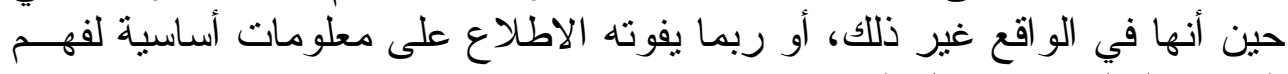

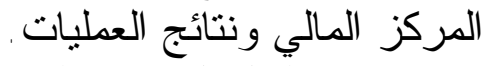

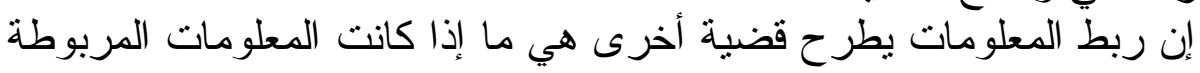

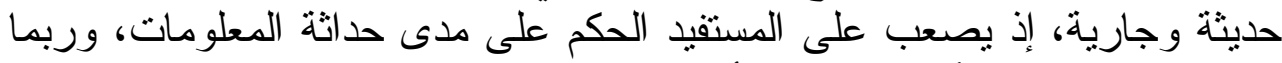

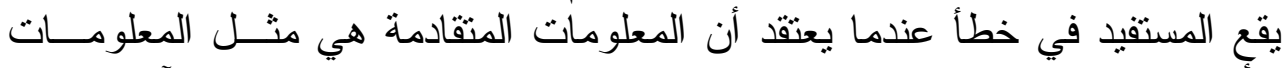

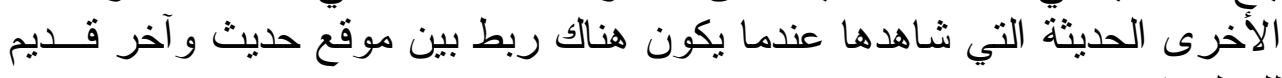

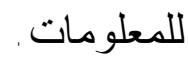




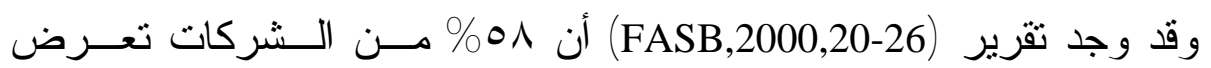

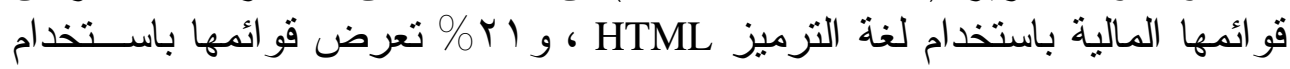

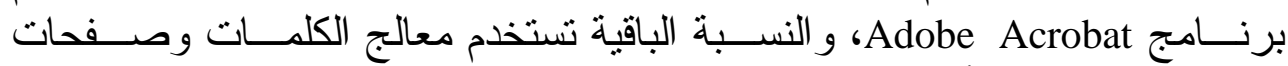

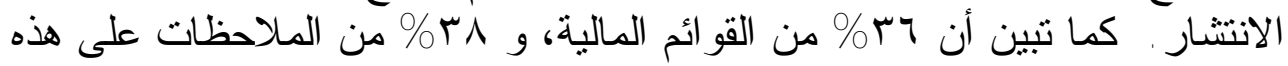

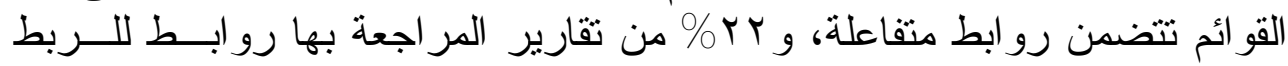
بالملاحظات الواردة بتقرير المراجعة.

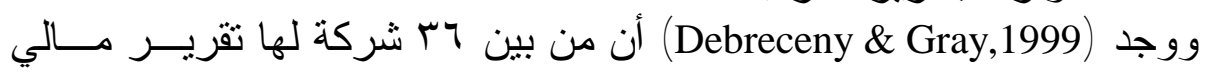

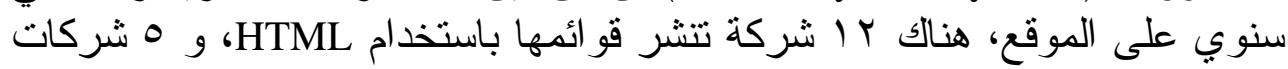

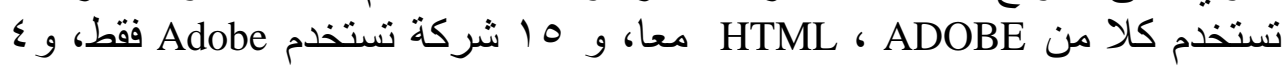

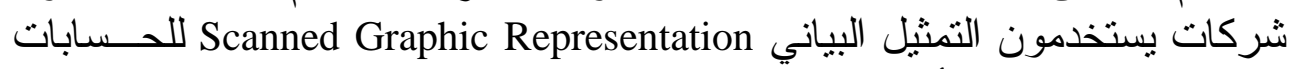

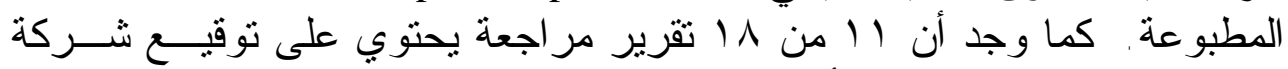

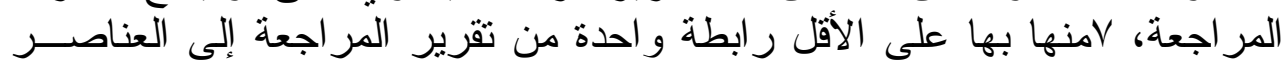

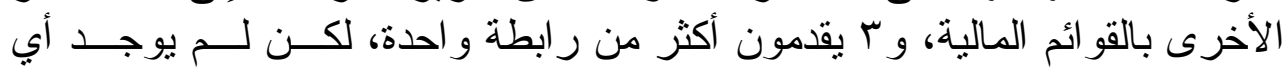

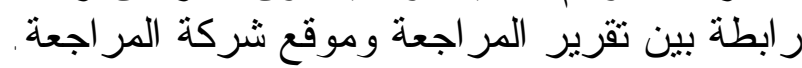

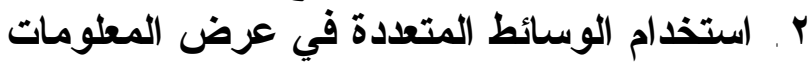

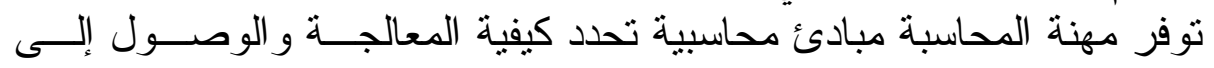

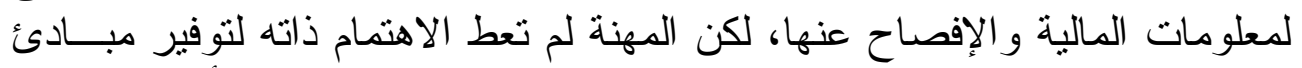

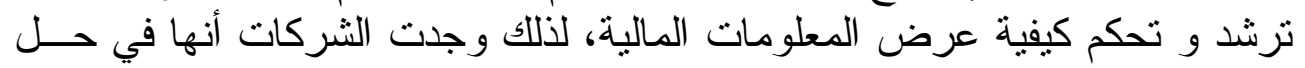

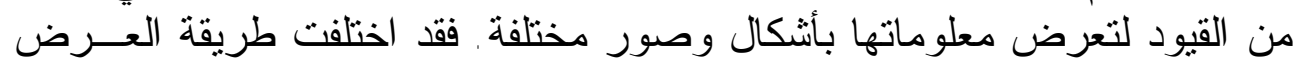

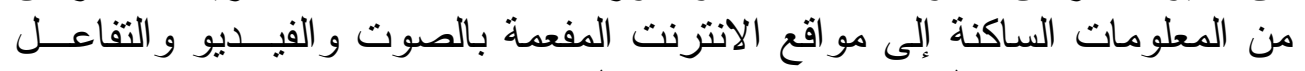

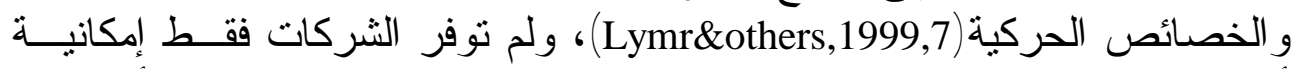

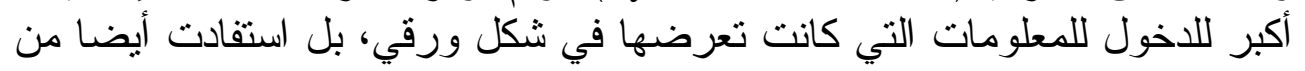

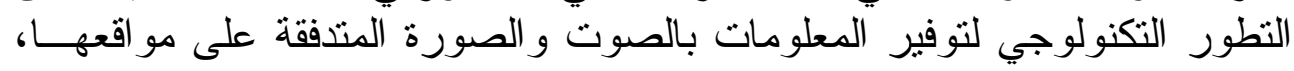

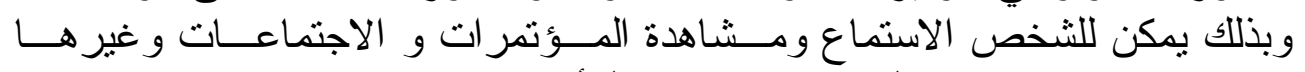

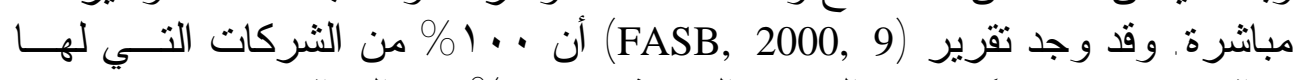

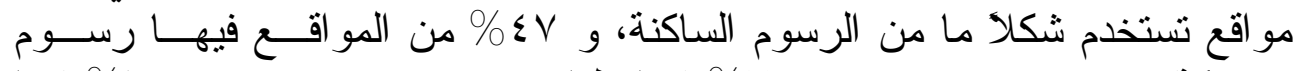

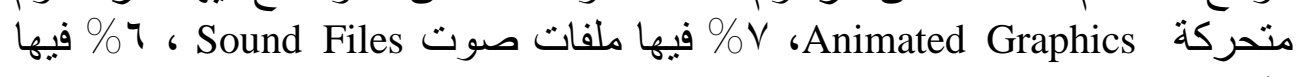
ملفات فيديو Video Files

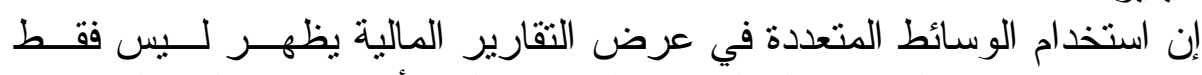

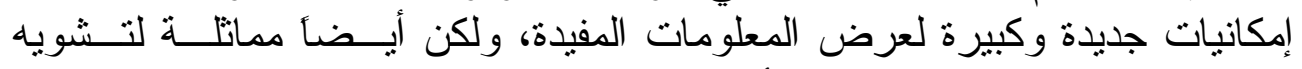

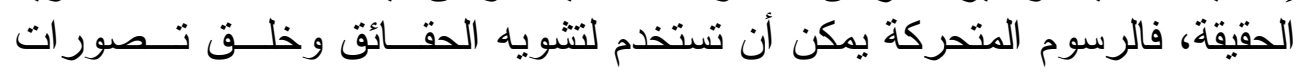

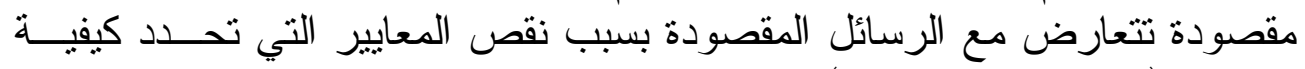
العرض (Trites,1999, 56-68). 


\section{r. عرض معلومات مالية غير مدققة}

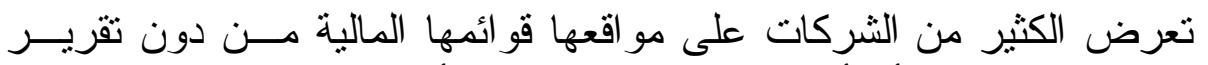

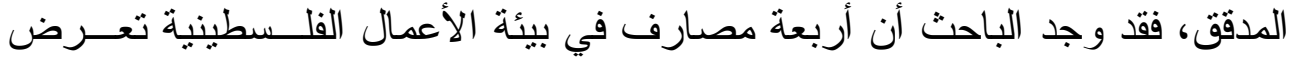

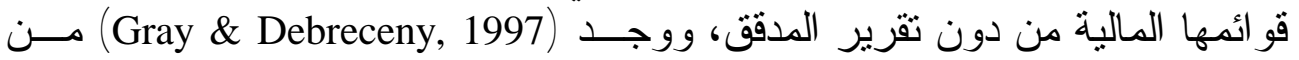

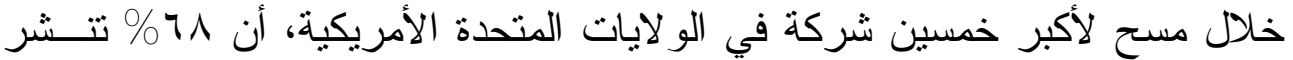

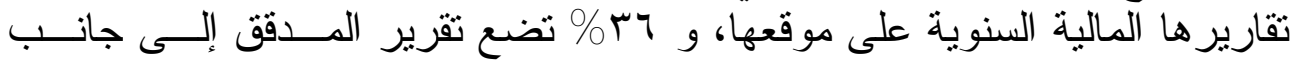

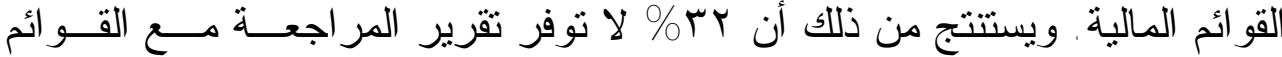

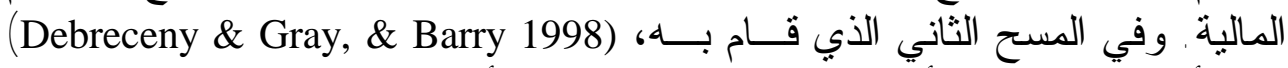

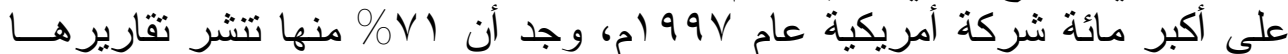

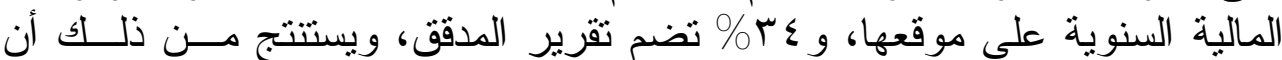

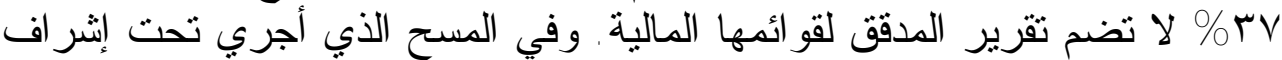

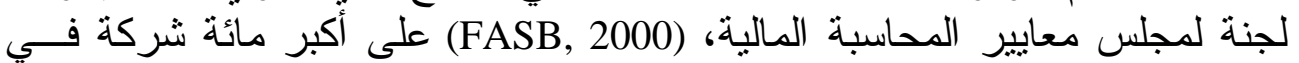

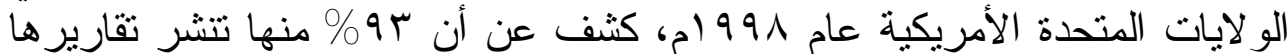

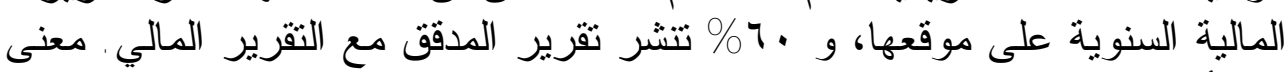

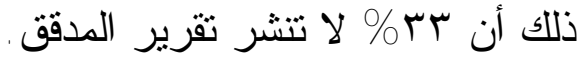

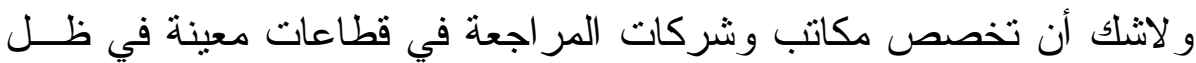

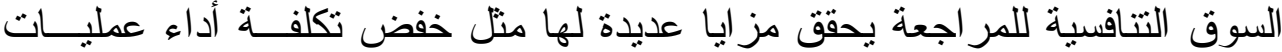

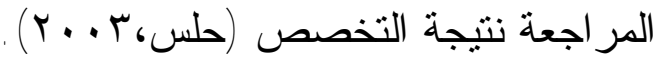

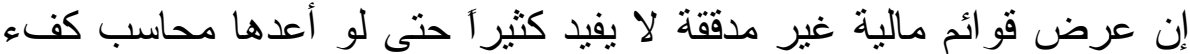

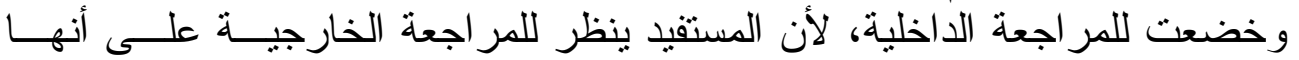

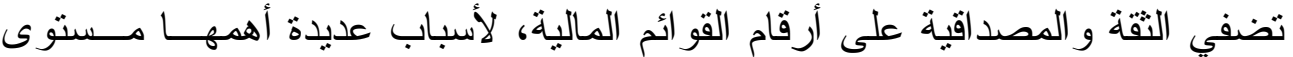

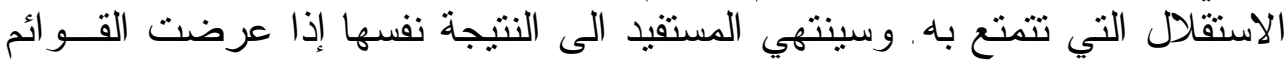
المالية المر اجعة من دون تقرير المدقق .

\section{؛ . عرض معلومات طوعية خارج نطاق القوائم المالية}

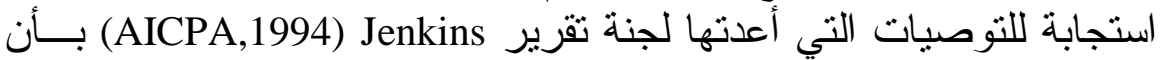

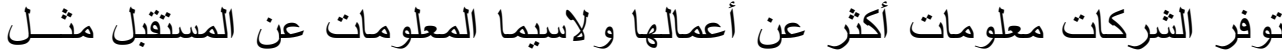

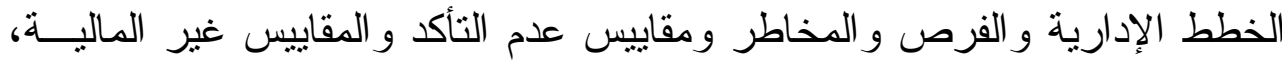

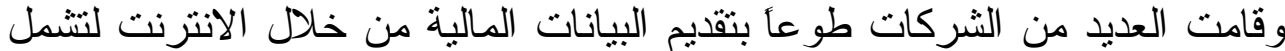

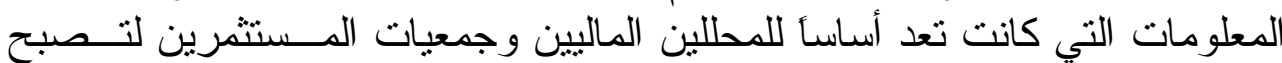

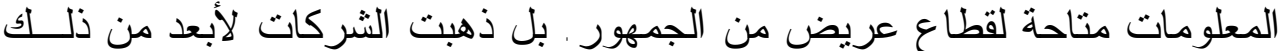

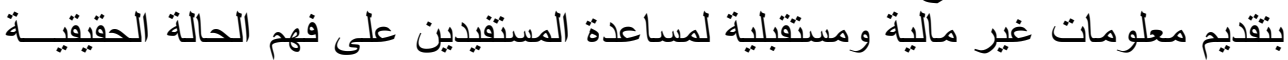

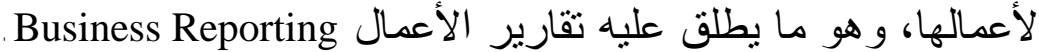

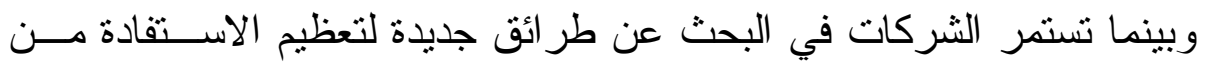

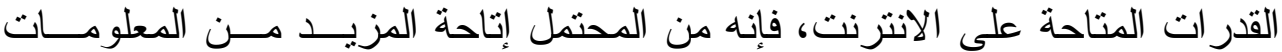

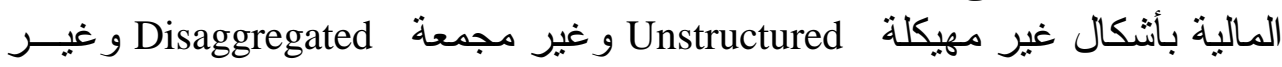




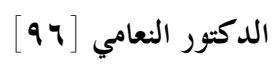

معيارية و التي تختلف تماماً عن الأشكال المعيارية المألوفة للقو ائم المالية، كما أنسـهـ

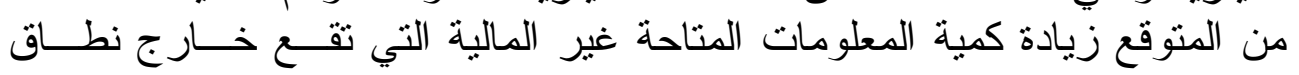

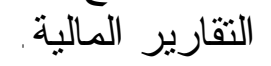

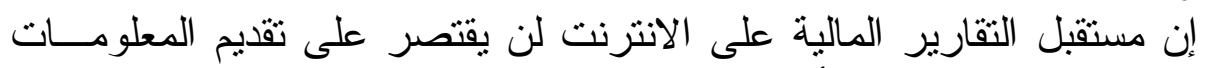

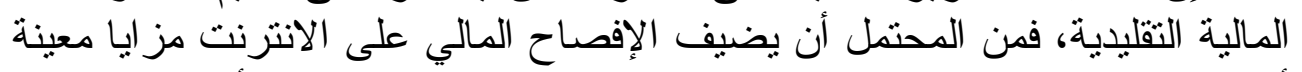

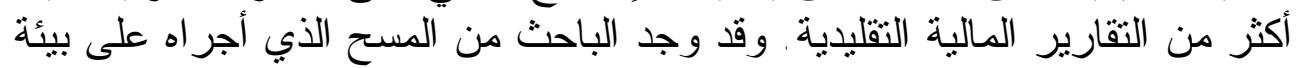

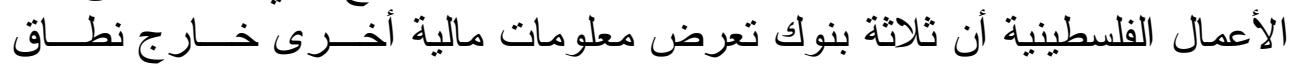

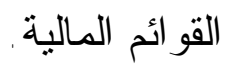

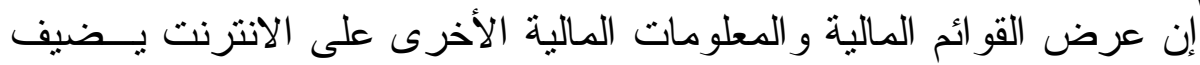

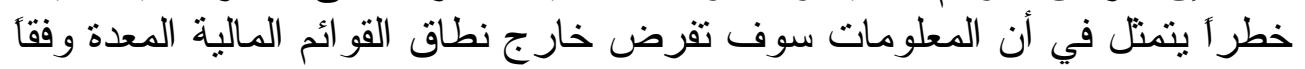

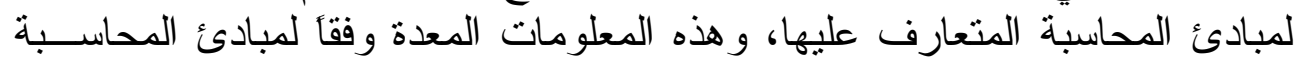

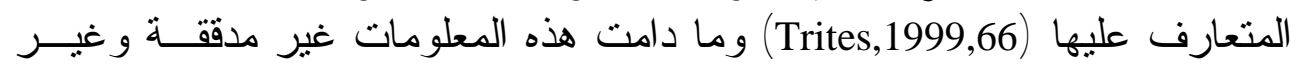
صادقة فلن تكون ذات فائدة كبيرة للمستقيد .

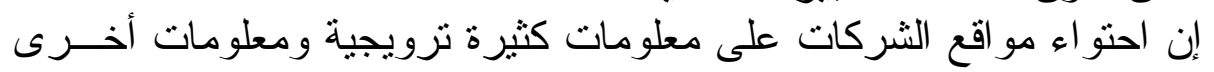

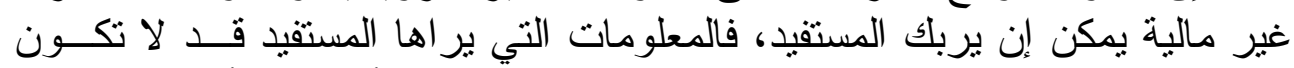

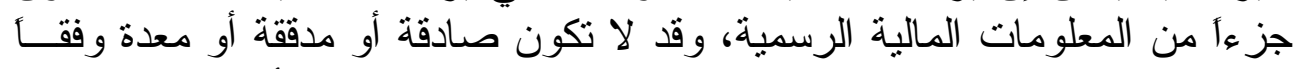

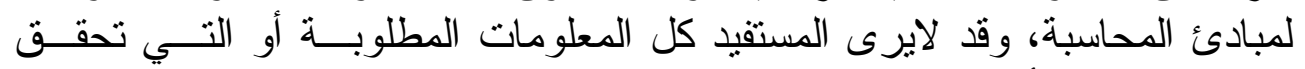

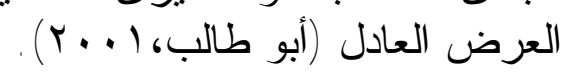

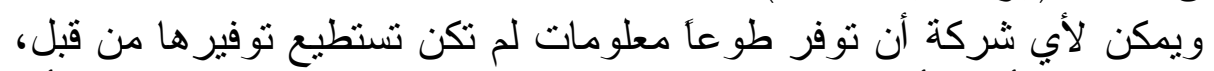

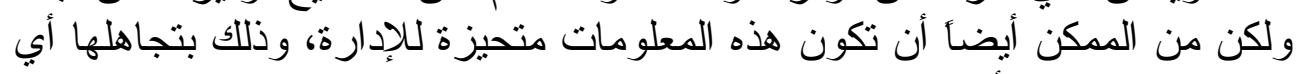
سلبيات عن بعض أمور الثركة (Molerof others,1999, 75)

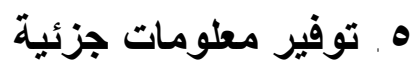

تتشر بعض الثركات المعلومات المالية على الانترنت من دون إحدى القدات القوائم

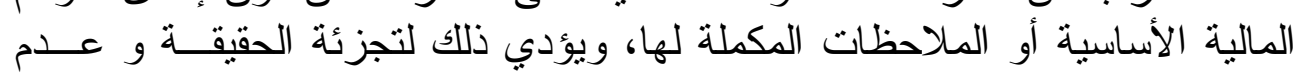

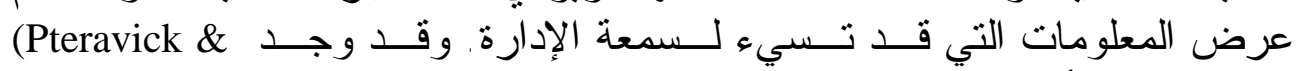

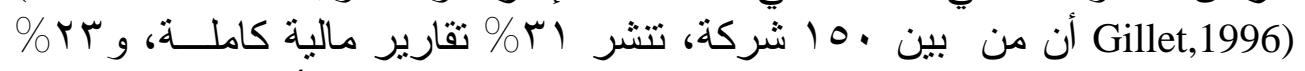

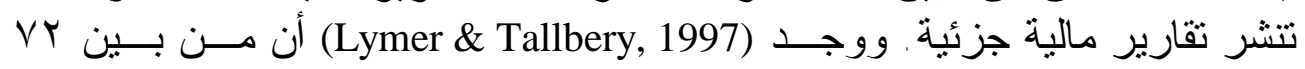

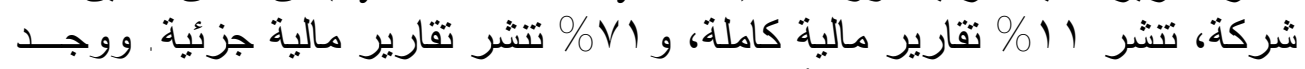
(Craven \& Marston,1999)

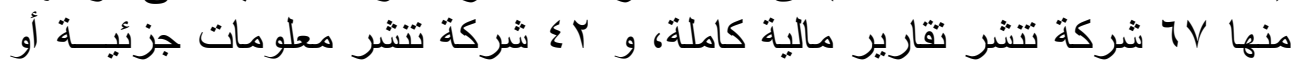
ملخصة.

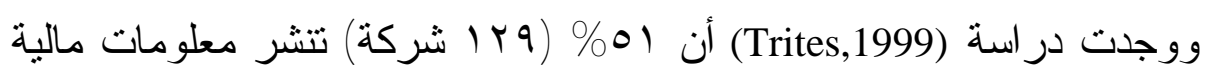

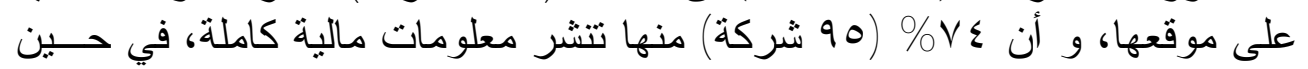

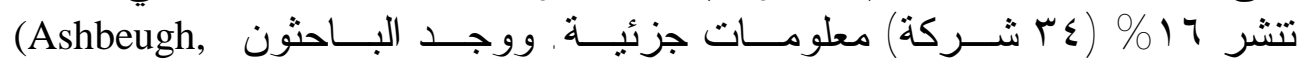


\% NV أن من بين · Johnstone, \& Warfied 1999)

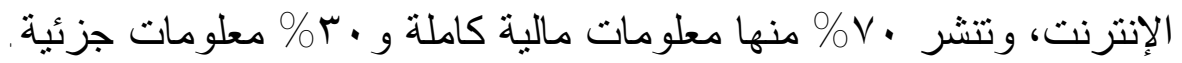

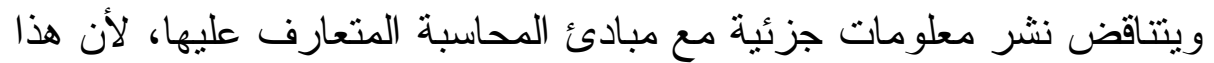

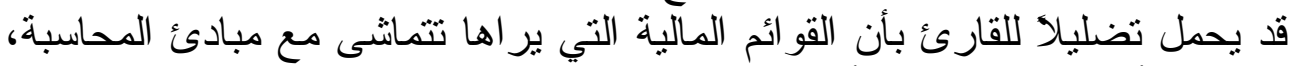

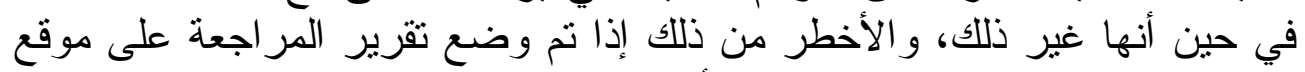

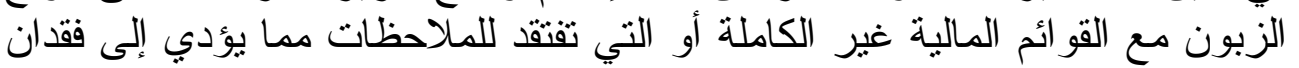

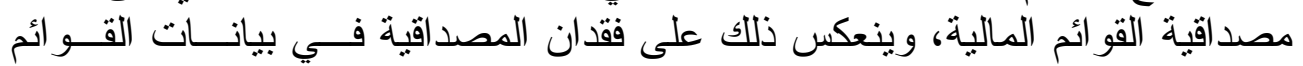

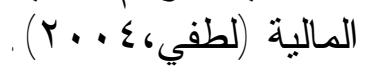

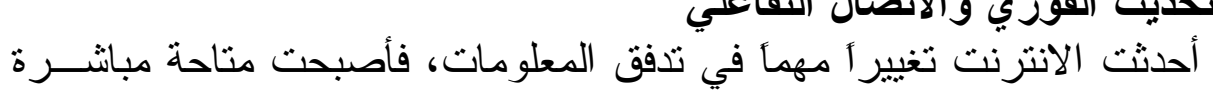

7 ـ التحديث الفوري والاتصال التفاعلي

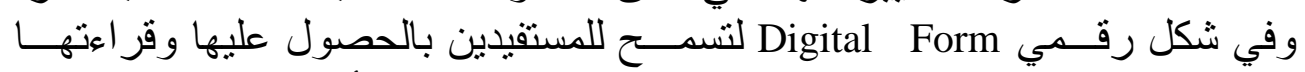

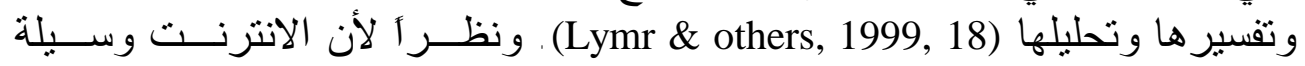

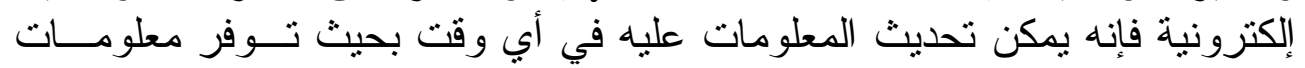

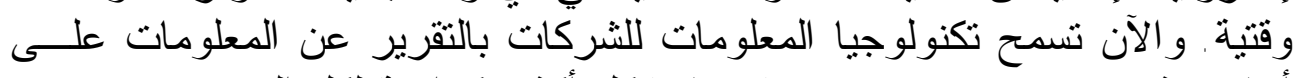

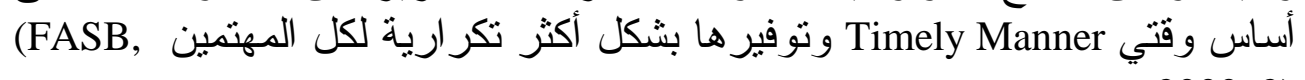
2000, 2)

و وتتيح الانترنت للمستقيدين إمكانية الدخول إلى المعلومات بأســلـوب معقــول

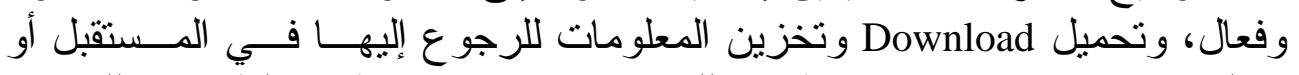

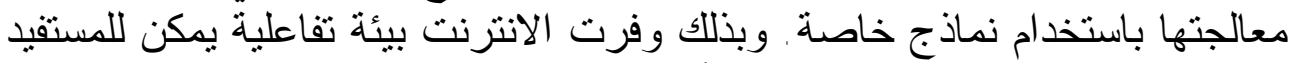

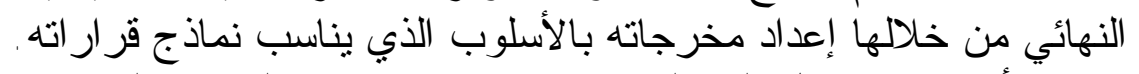

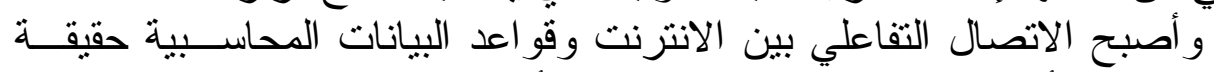

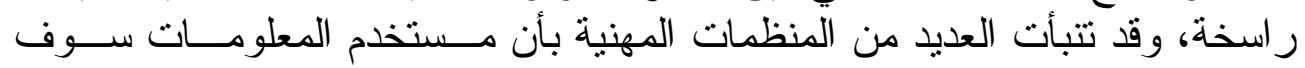

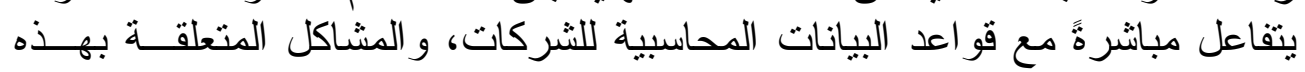

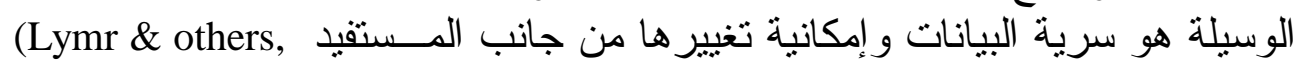

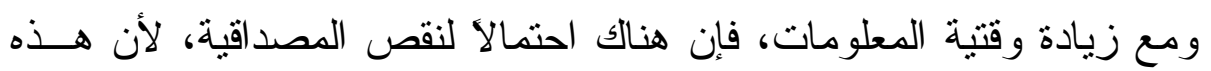

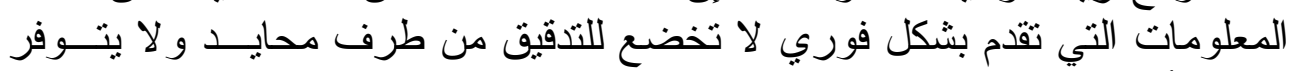

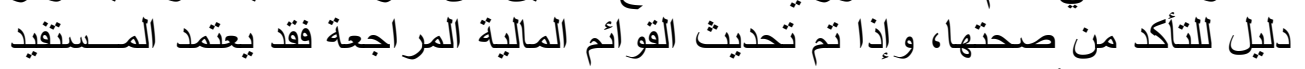

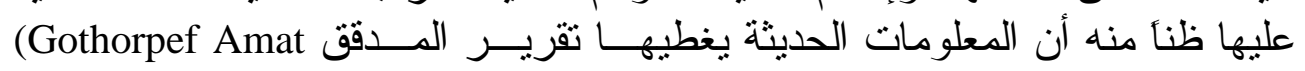
.1999,358)

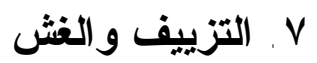
من الصعب تغيير تقرير المر اجعة أو توقيع شركة التدقيق عندما يكون ضمن المن فئن

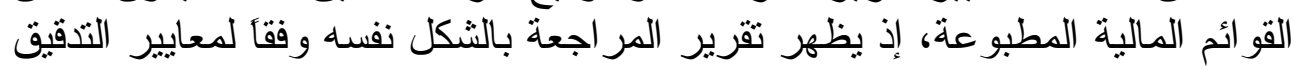

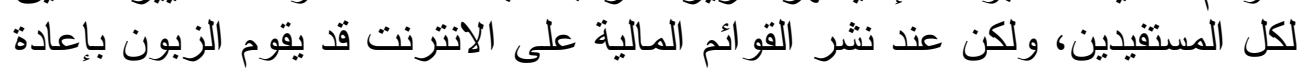




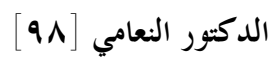

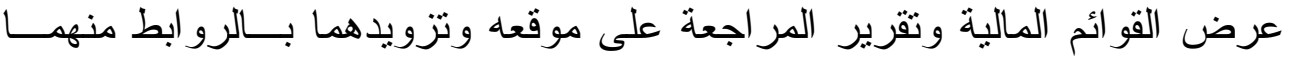

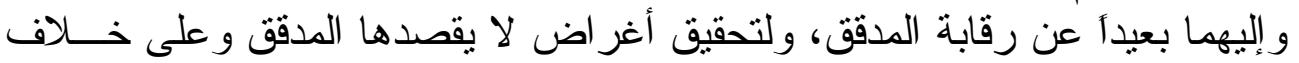

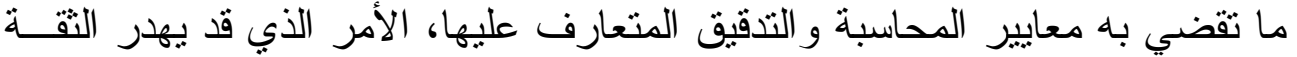

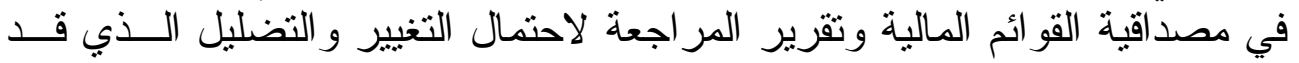

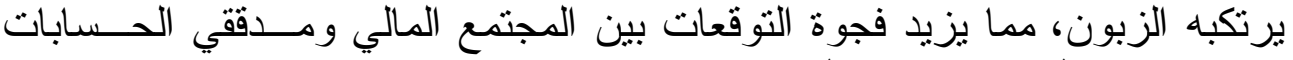

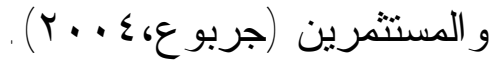

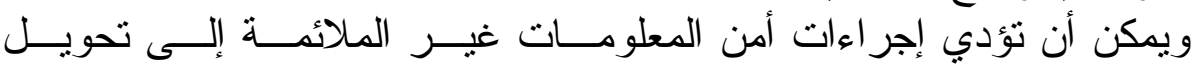

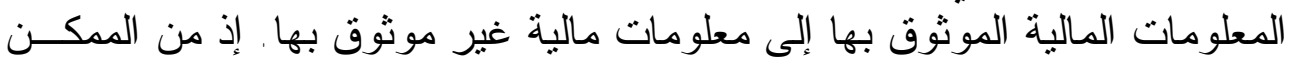

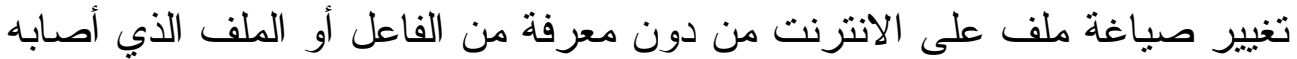

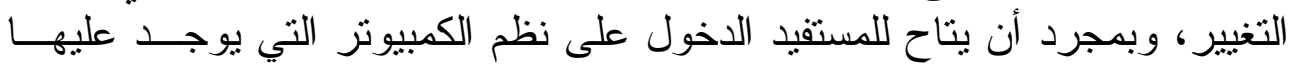

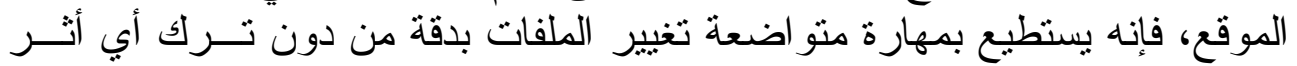

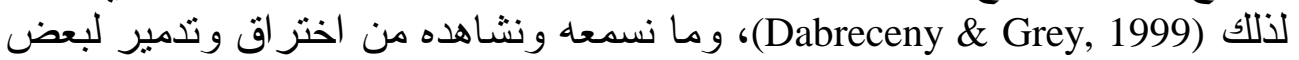

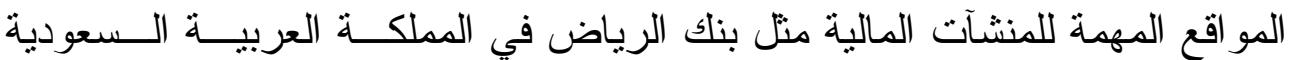

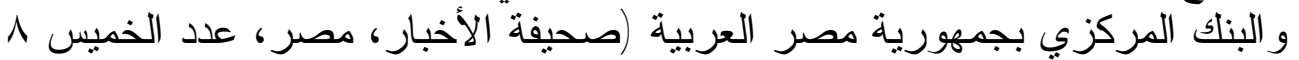
فبر اير ( . . ب) لاليل على إن نقص الأمن على الانترنت يشكل عقبة في استخدامها في مجال الأعمال خاصة التجل التجارة الالكترونية.

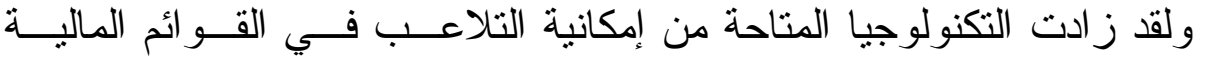

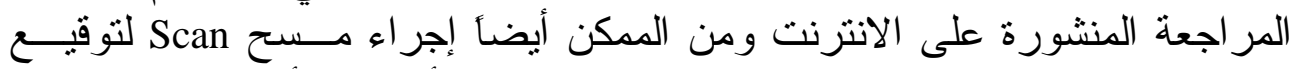

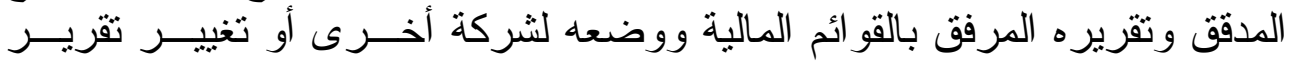

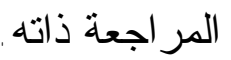

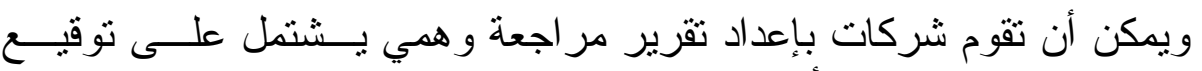

مزيف لشركة مر اجعة حقيقية أو و همية (Stevens, Michael G, 1999).

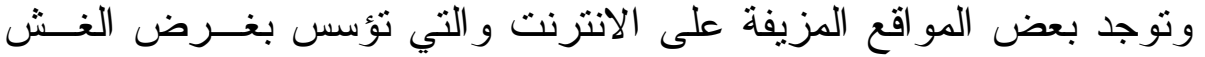

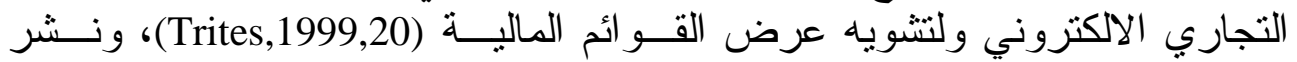
معلومات مضللة عن الأداء المالي و التشغيلي للثشركة.

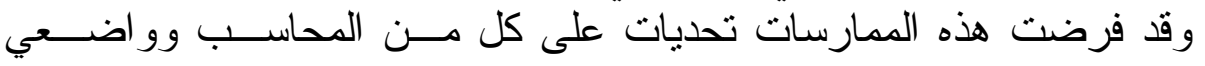

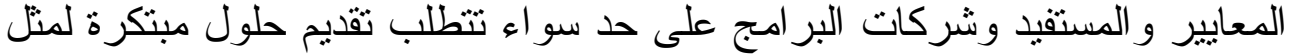

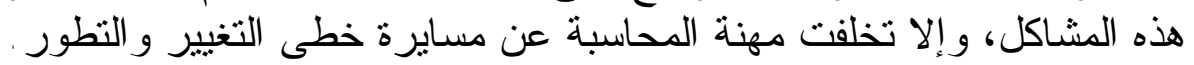

\section{الحلول المستخدمة والمقترحة}

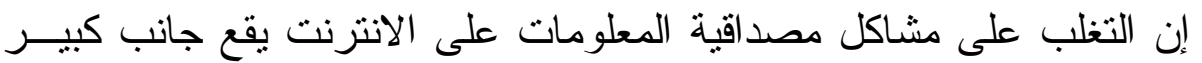

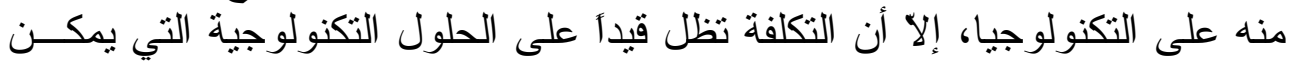

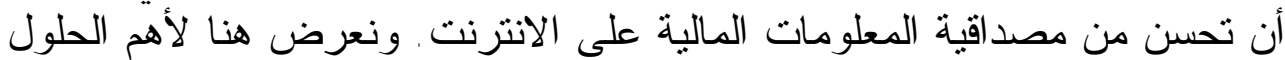

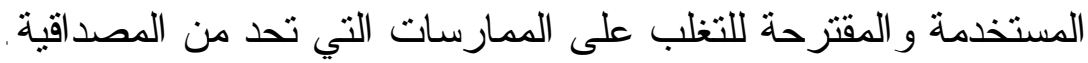

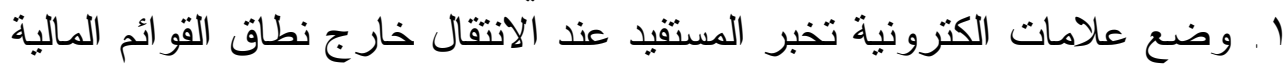

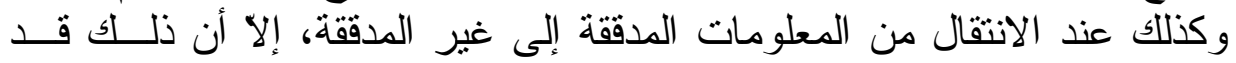




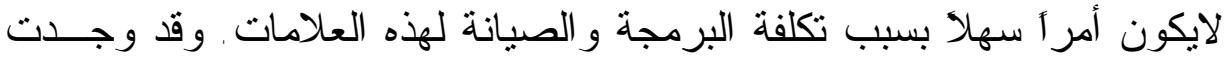

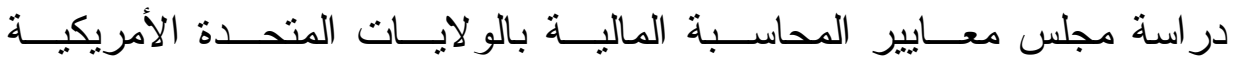
(FASB,2000,23)

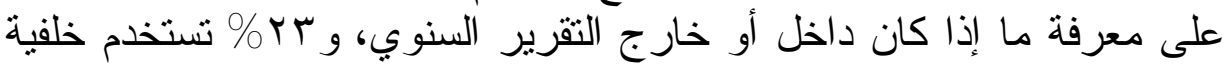

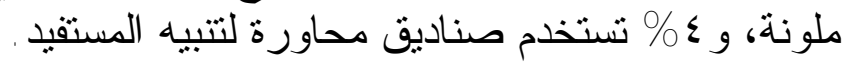

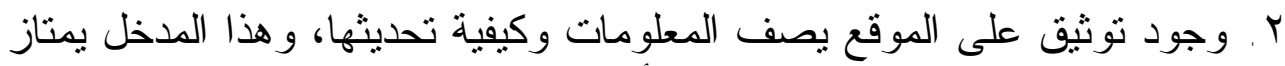

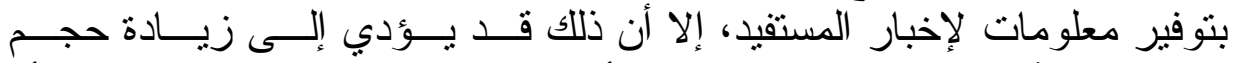
المعلومات بأكثر مما ينبغي، فضلا لإل عن أن هذه المعلومات قد لا تكون حديثة أو دقيقة.

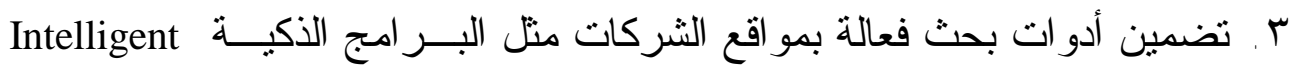

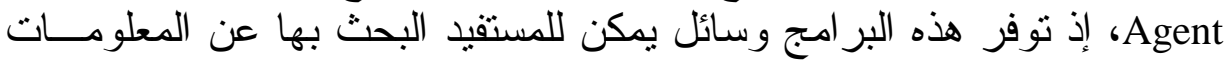

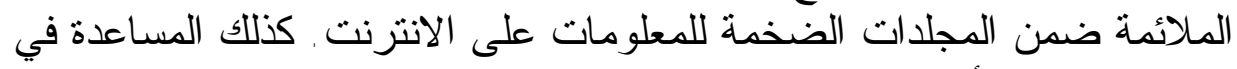
تصنيف وتحديد أولوياته (Baldwin \& Williams, 1999).

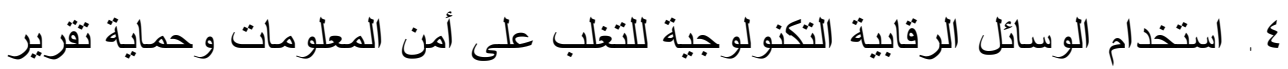

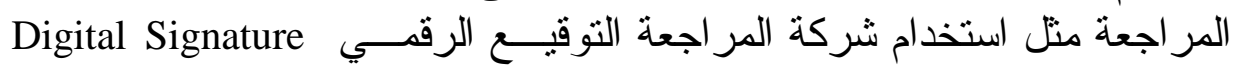

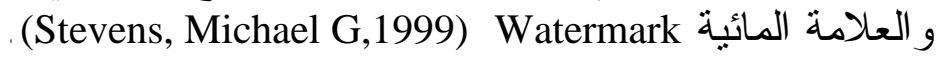

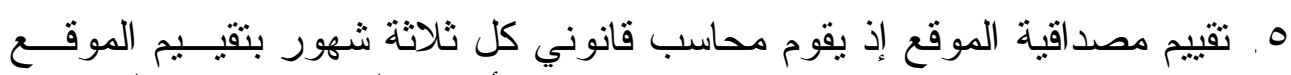

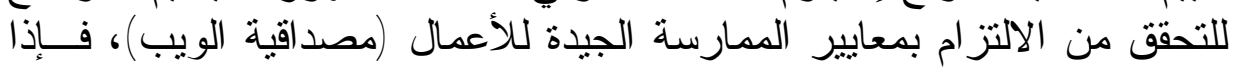

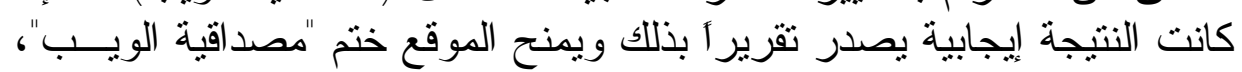

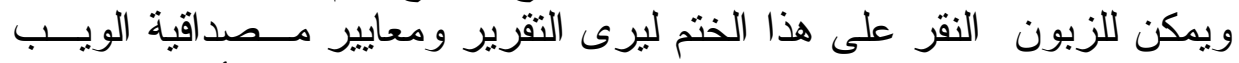

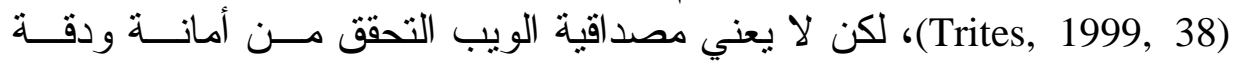
البيانات على الموقع.

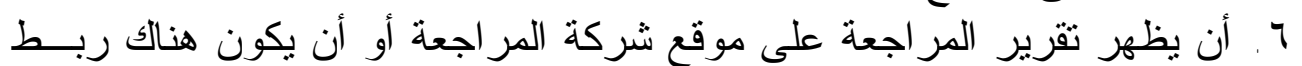

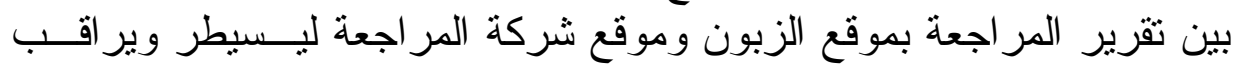
المدقق على شكل تقريره ومحتو اه (لبرن (Dabreceny \& Grey, 1999). ويضيف الباحث إلى الحلول السابقة الآتي:

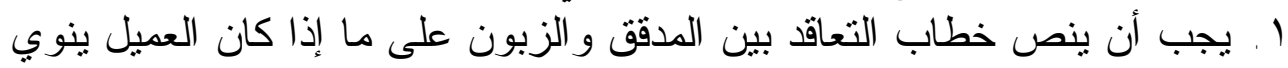

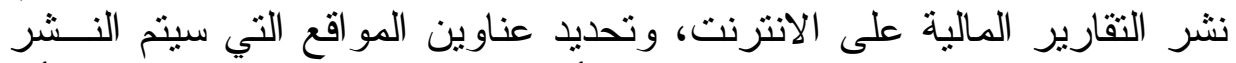

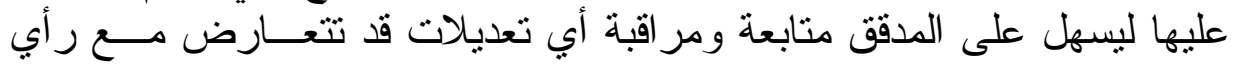

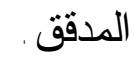

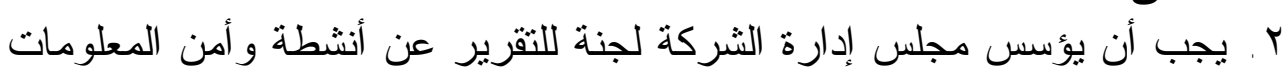

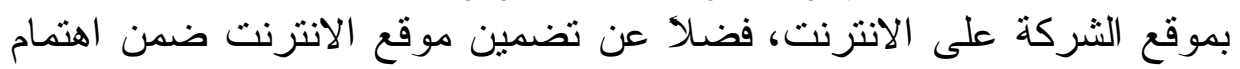

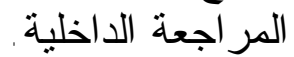

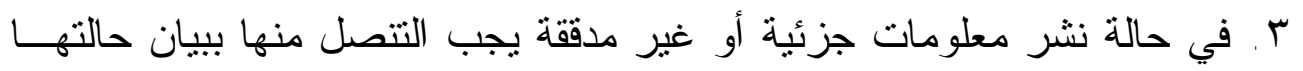

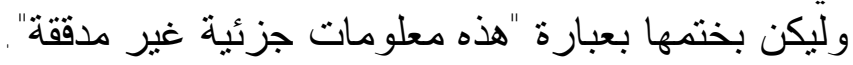




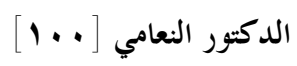

ـ ـ إصدار المعايير ووضع الإرشادات التي تحدد كيفية عرض المعلومات الماليــة

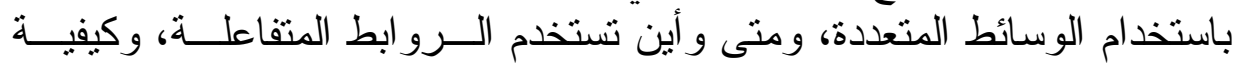
التحقق من المعلومات الفورية و الثقاريز المستمرة.

ثالثاً - حدود المدقق ومسؤوليته

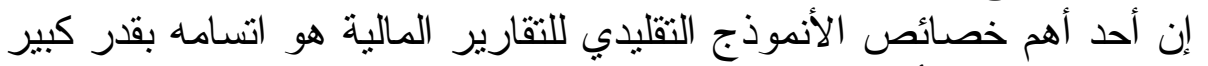

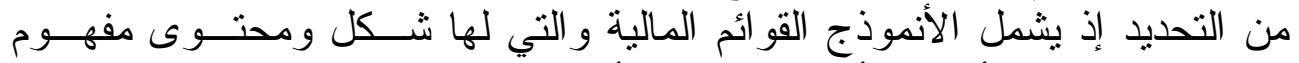

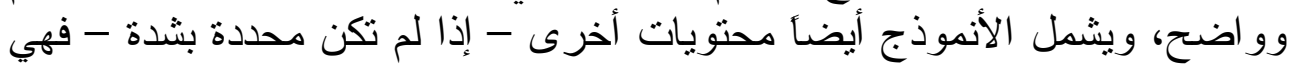

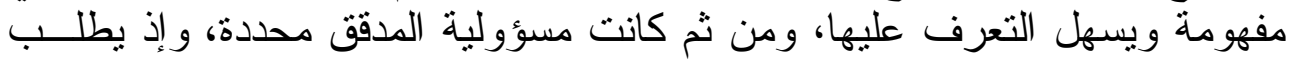

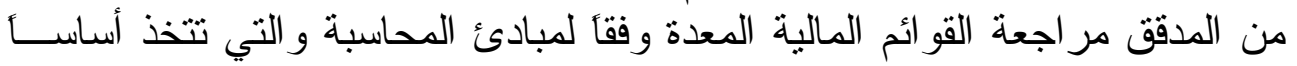

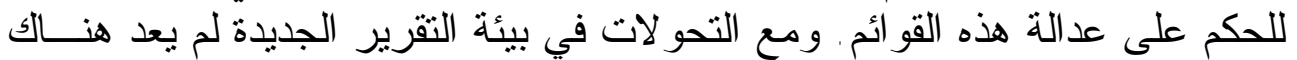

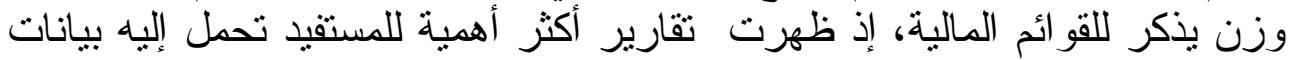

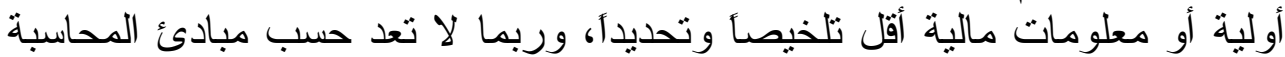

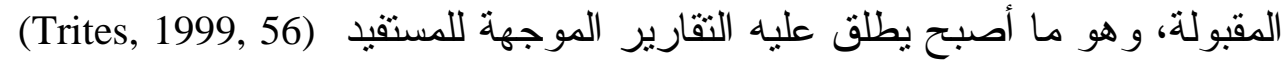
بالفئ كiser - Designed Reports

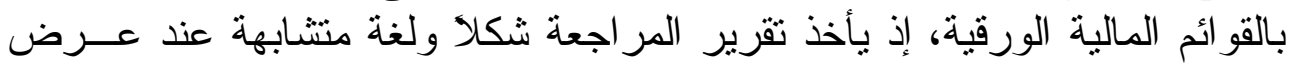

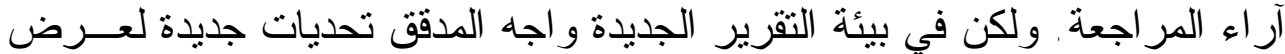

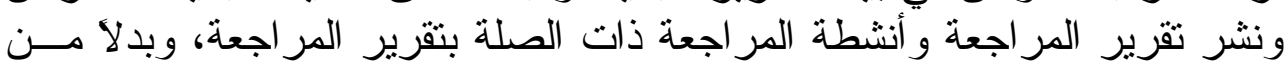

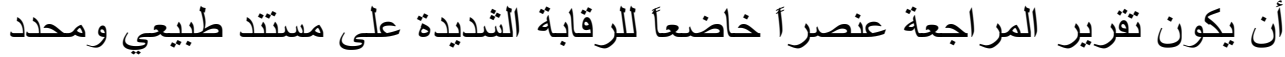

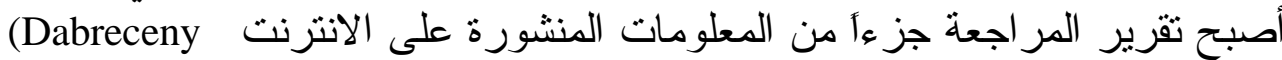
(Grey, 1999 \& . ويناقش الباحث مسؤولية المدقق في ظل بيئة التقرير الجديدة.

\section{ا ـ المسؤولية عن سلامة وأمن المعلومات على الانترنت}

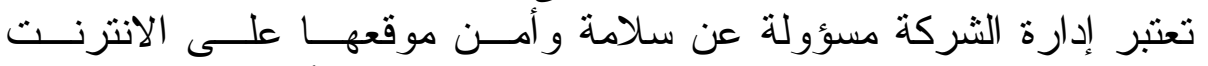

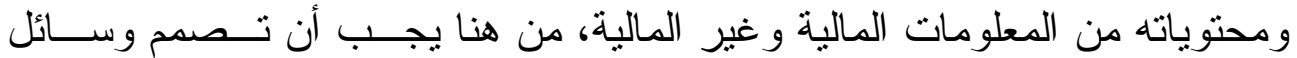

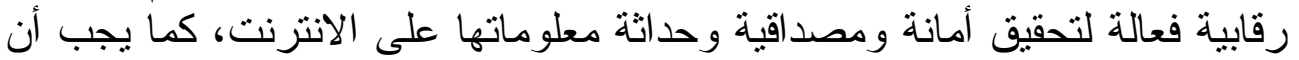

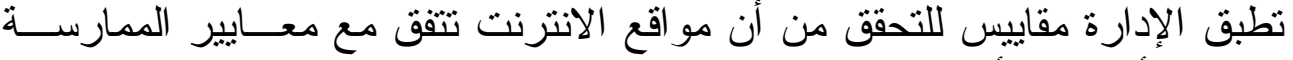

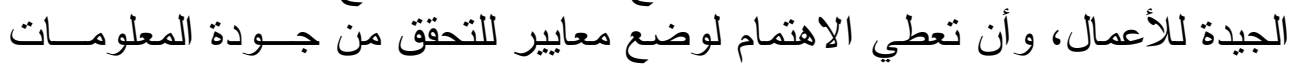

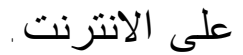

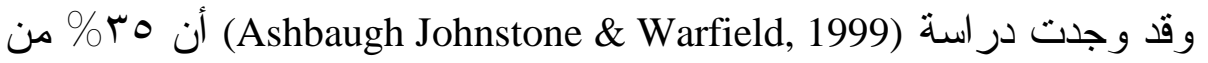

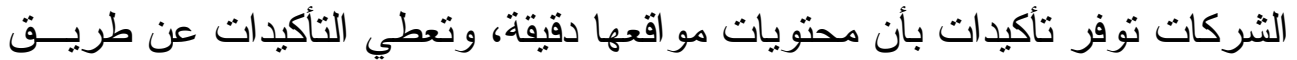

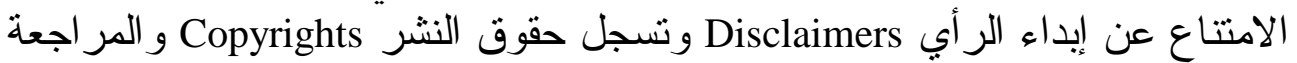
بوساطة المسؤولين عن الويب Web Masters أو بوساطة جهة مهنية الئي . Agency

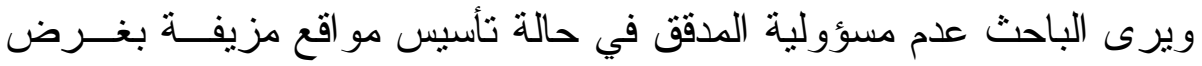

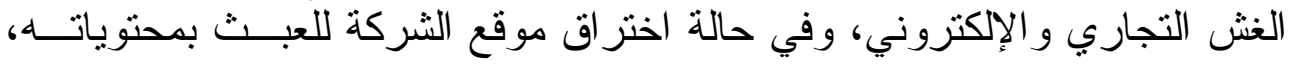




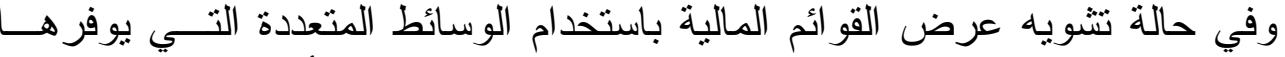
الانترنت، وفي حالة نشر معلومات جزئية غير مر اجعة عن الأداء المالي و التشغيلي الئي

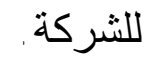

\section{r ـ المسؤولية عن القوائم المالية المراجعة وتقرير المراجعة}

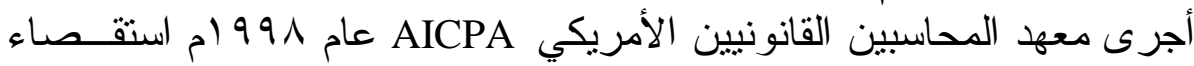

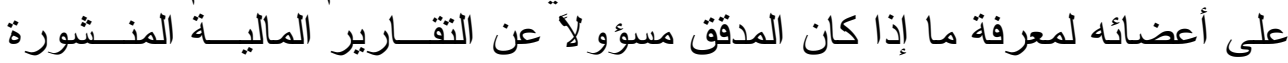

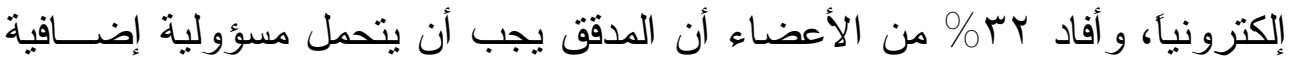

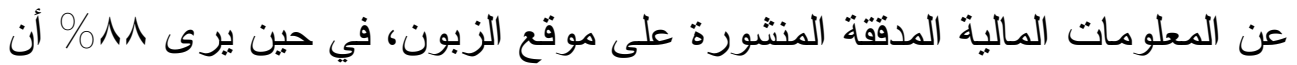

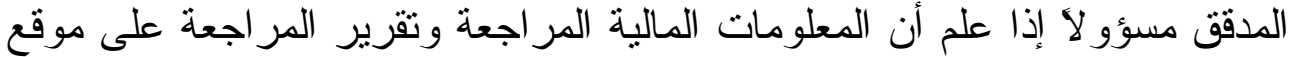

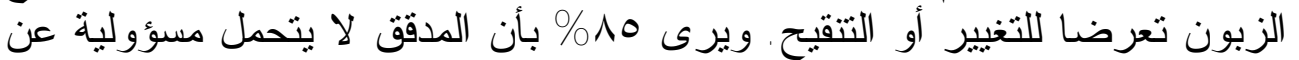

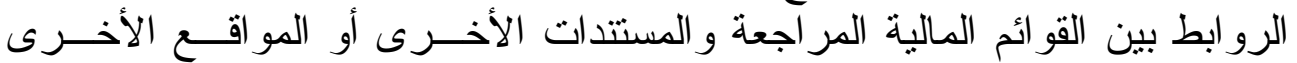

(Dabreceny \& Grey, 1999)

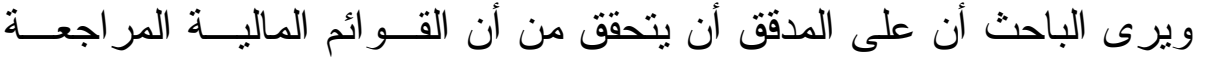

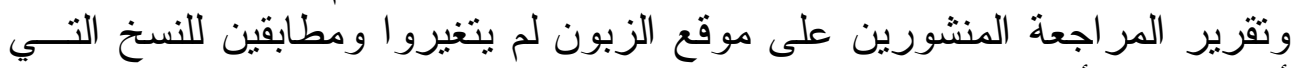

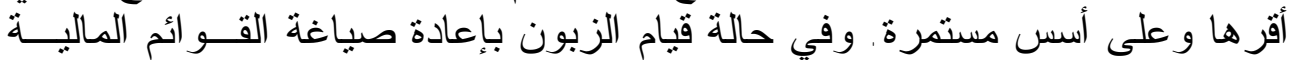

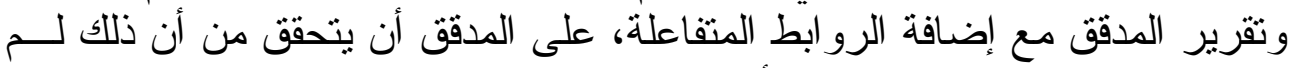

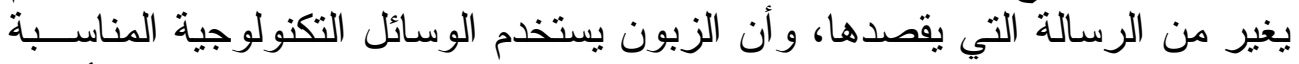

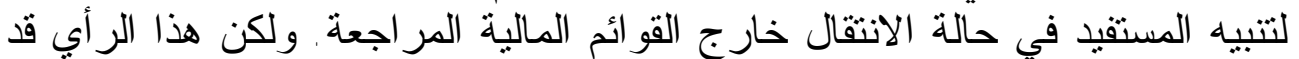

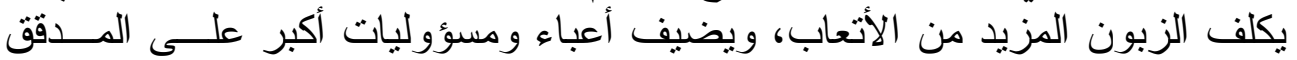

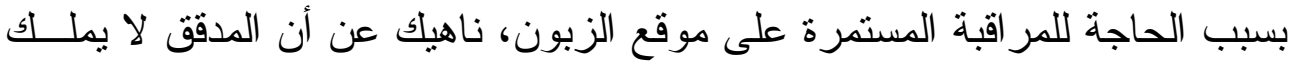

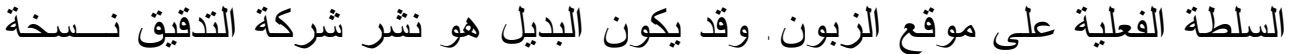

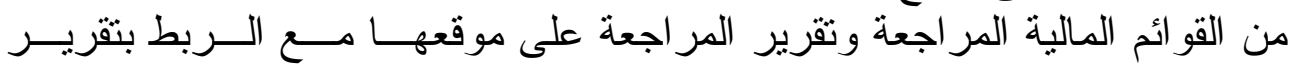
المر اجعة الظاهر على موقع الزبون.

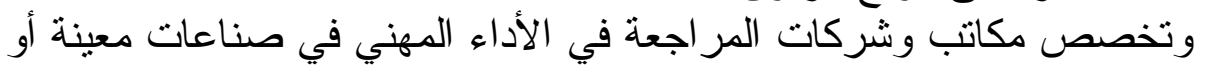

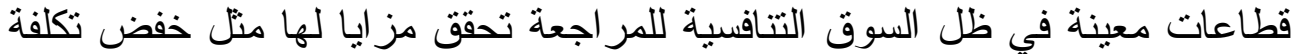

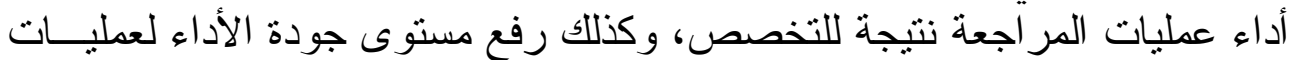

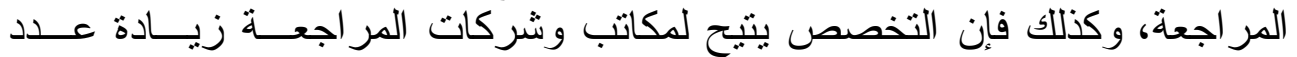

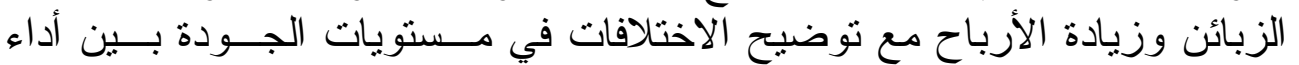

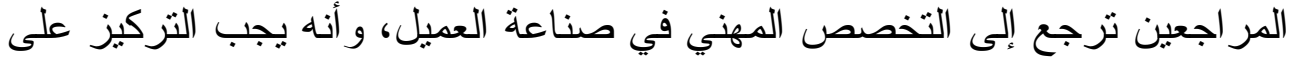

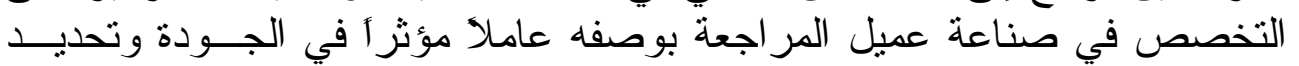

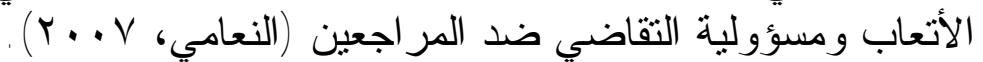

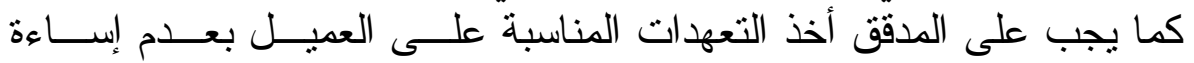
استخدام تقرير المر اجعة، في حالة نشره على التى الانترنت، بوضعاه مع معلومات مالية جزئية أو غير مر اجعة. 


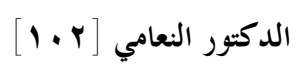

r ـ المسؤولية عن المعلومات التي تقع خارج نطاق القوائم المالية

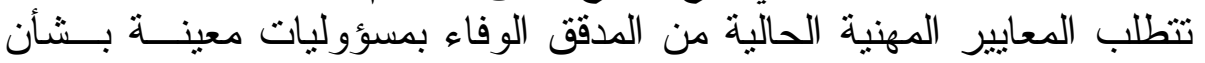

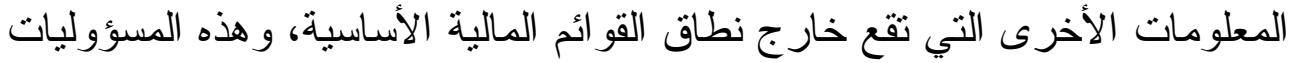

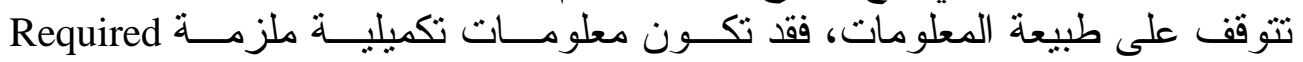
Supplementary Information المات . Voluntary Information

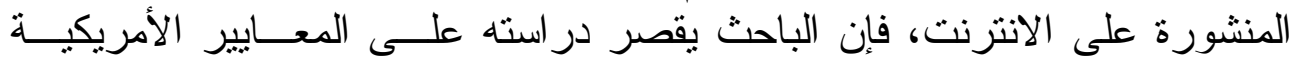
و البريطانية.

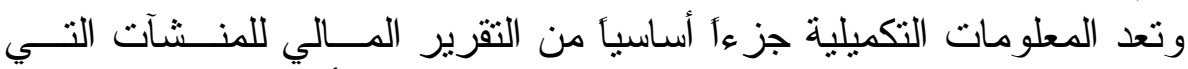

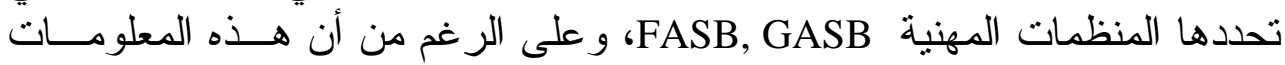

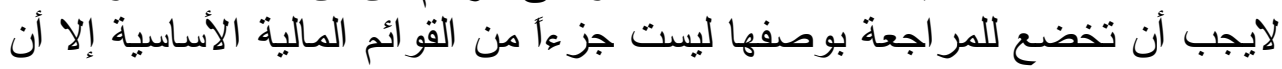

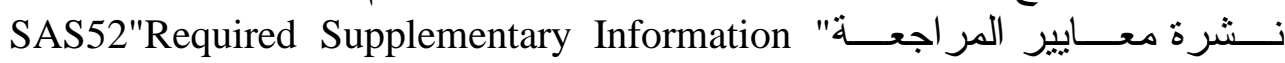
Certain Limited تتطلب تطبيق إجر اءات محدودة معينـة (Balley, Larry 10-18) Procedures • التأكد من أن المنظمات المهنية FASB, GASB تطلب من المنشأة الإفصاح عن المعلومات التكميلية.

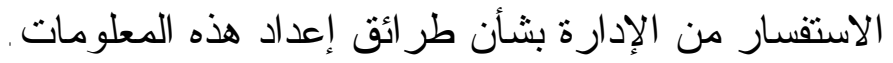

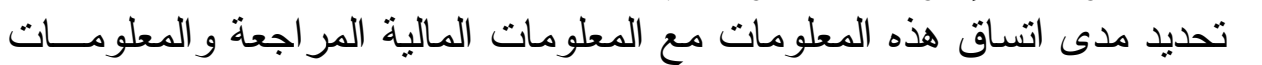

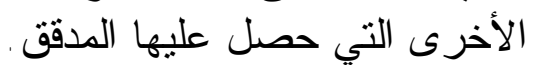

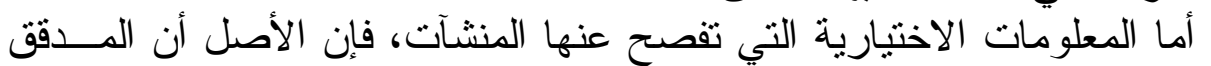
ليس مسؤو لا عن مر اجعة هذه المعلّومات، ولكن عليه أن يطبق بشأنها معايير مهنية

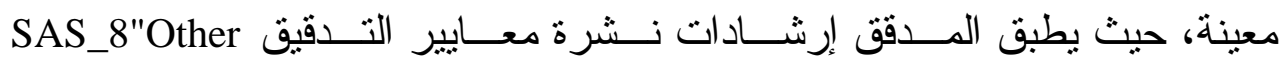
Information in Documents Containing Audited Financial Statements" تعرض هذه المعلومات مع القوائم المالية في مستتد أعده العميل، في حين يطبــق

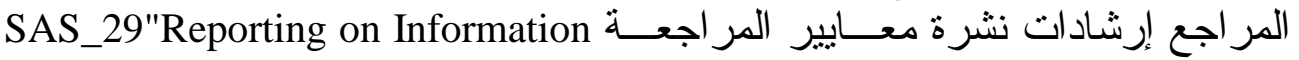
Accompanying the Basic Financial Statements in Auditor-Submitted عندما تعرض هذه المعلومات مع القوائم المالية في مسـتستد خـــع Documents" لفحص المدقق Auditor-Submitted Documents.

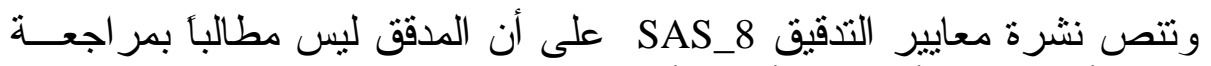

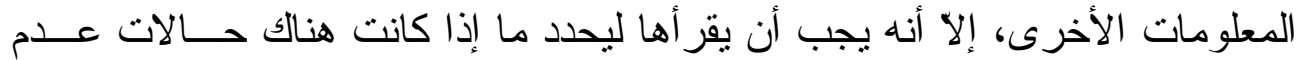

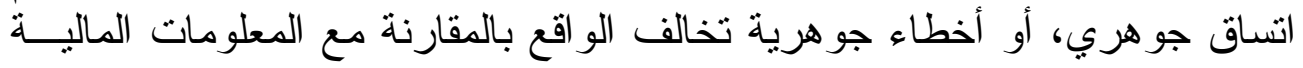

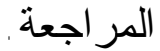

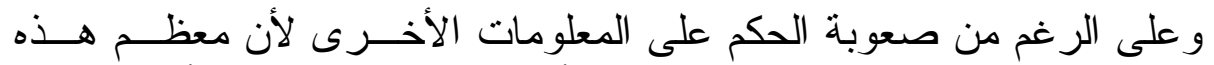

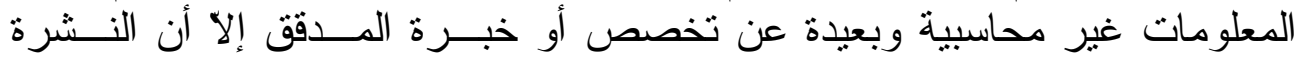
تذكر أن على المدقق أن يستخدم حكمه الثخصي وتقديره المهني، و إثعار 
العميل كتابةً عن الأخطاء الجوهرية بالمعلومات الأخرى وطلب المشورة القانونيـــة بشأن الخطوات الأخرى واجبة الإتباع (Balley, Larry11-43).

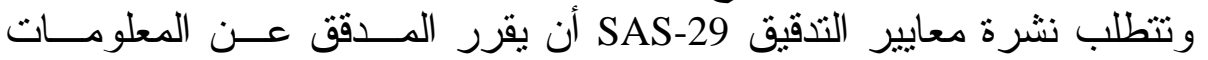

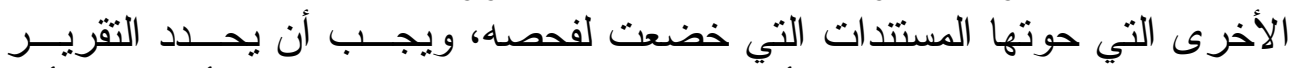

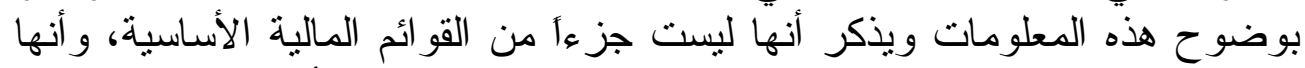

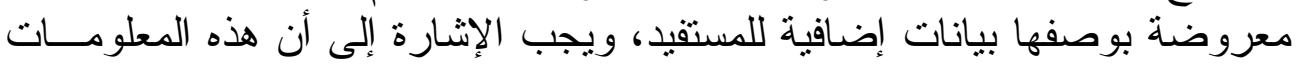

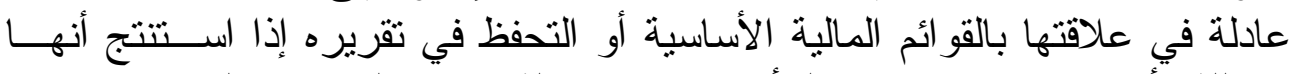

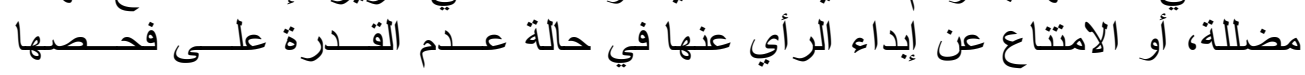
.(Balley, Larry11-49)

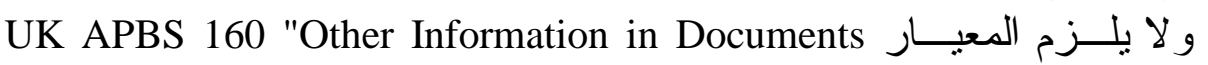
Containing Audited Financial Statements"

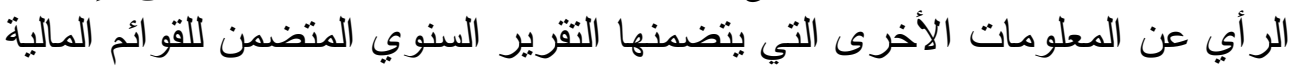

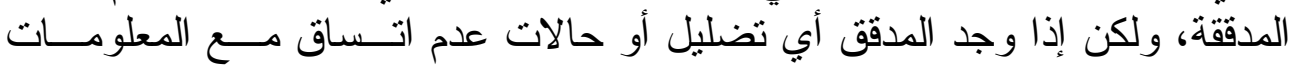

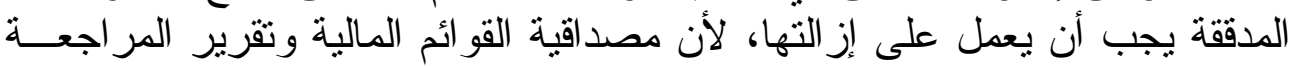
ربما تتخفض بوجود منل هذه الحالات (Dabreceny \& Grey, 1999)

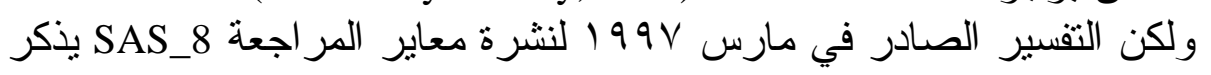

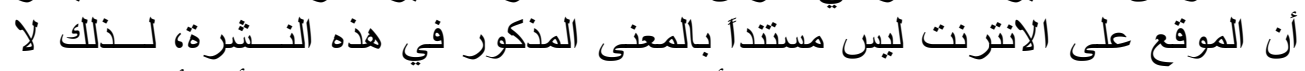

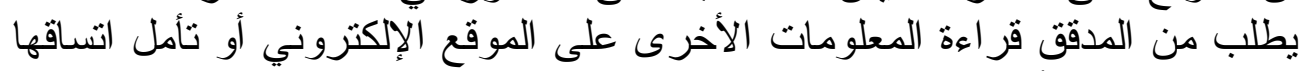
مع المستتدات الأصلية (Stevens, 1999).

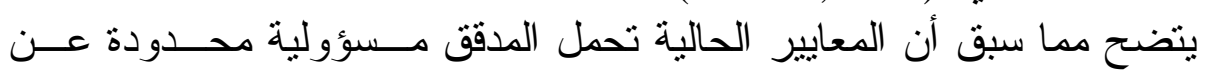

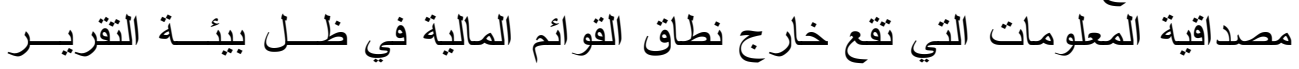

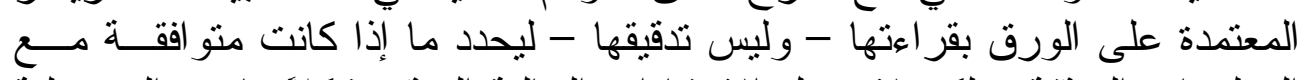

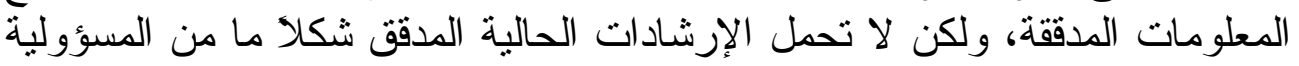

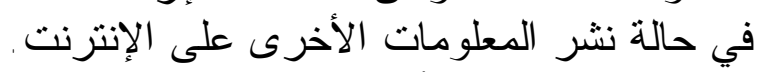

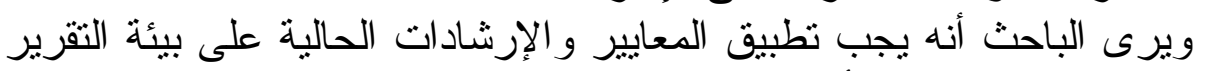

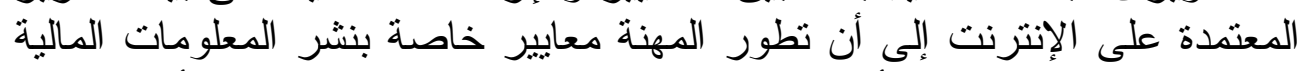

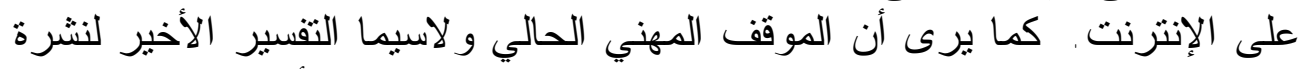

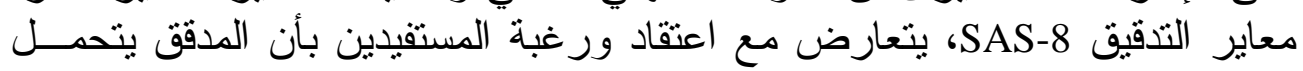

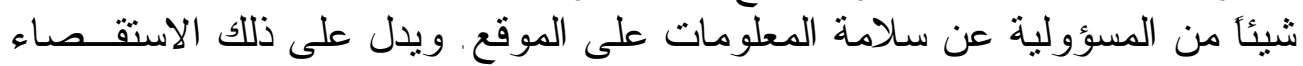

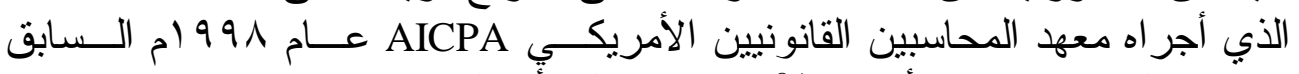

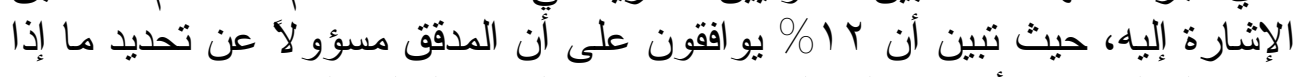

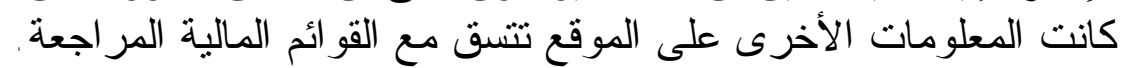

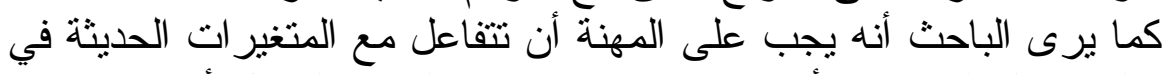

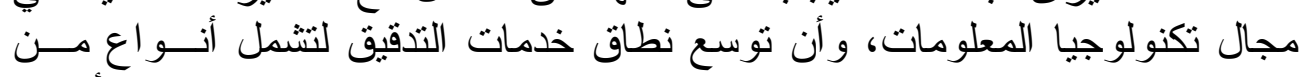

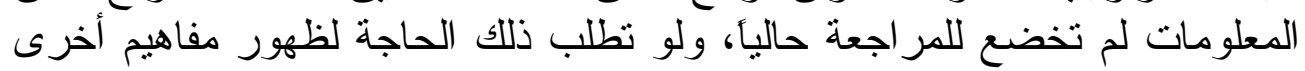

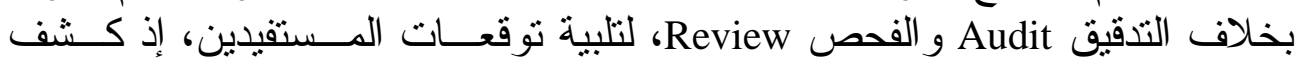




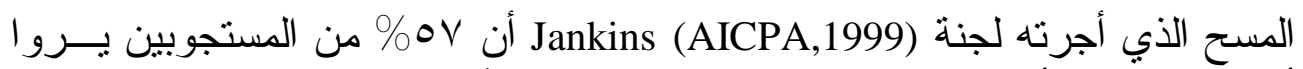

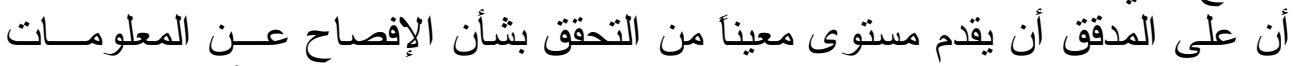

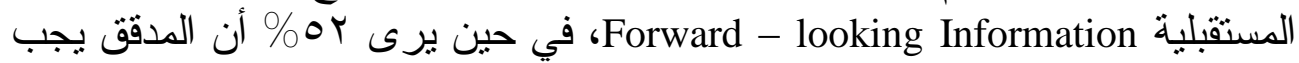

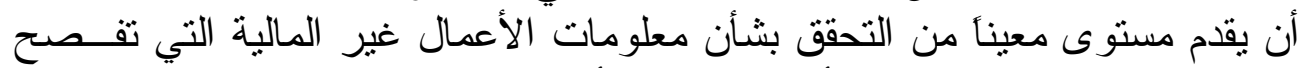

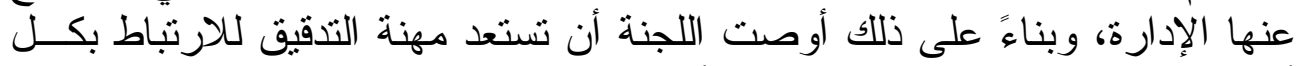

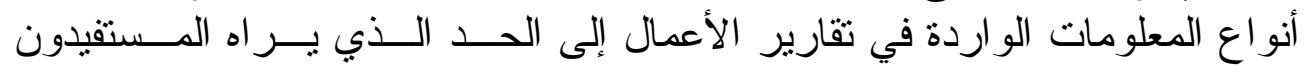
و الثركات ضرورياً.

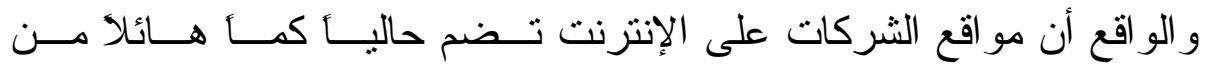

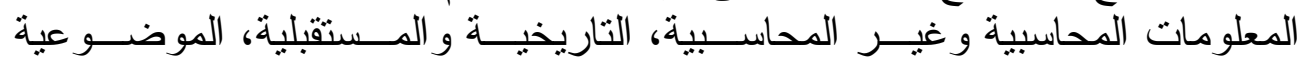

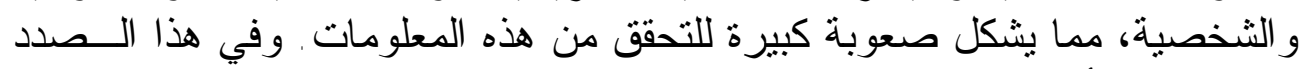

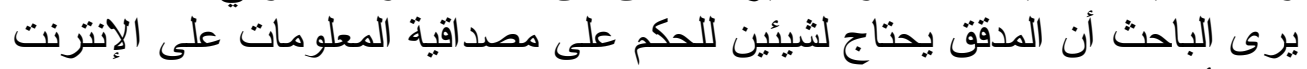

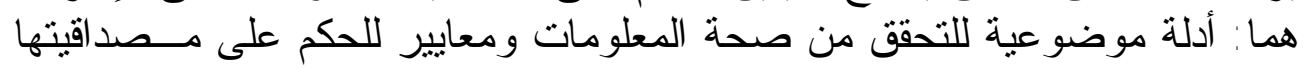

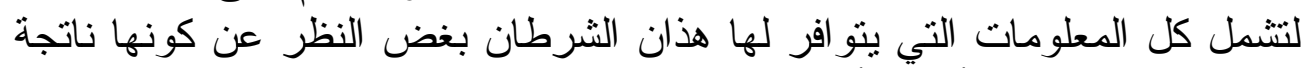

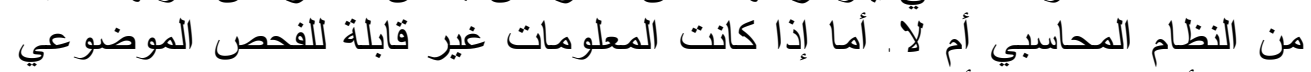

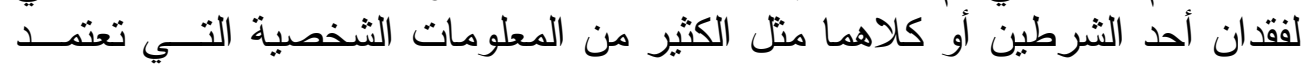

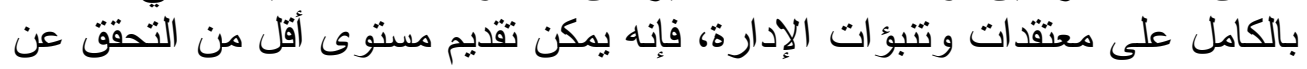

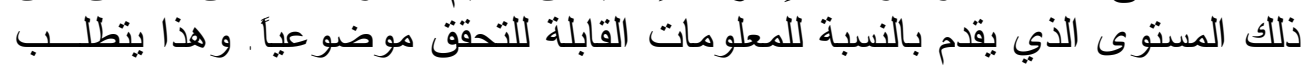

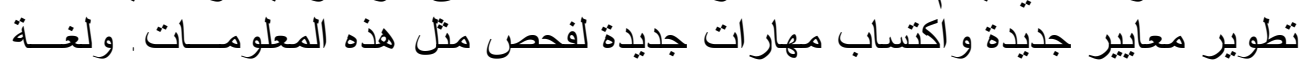
تقرير جديدة تعكس مستوى التحقق ومقدار المسؤولية التي يتحملها المدقق .

\section{؛ ـ المسؤولية عن التحديث الفوري للقوائم المالية}

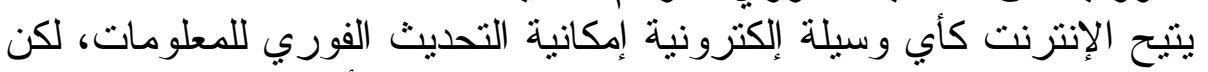

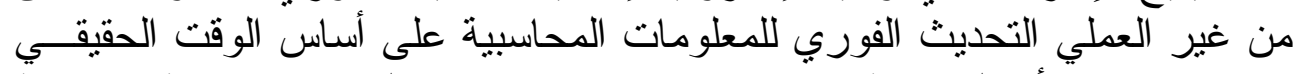
، Real Time

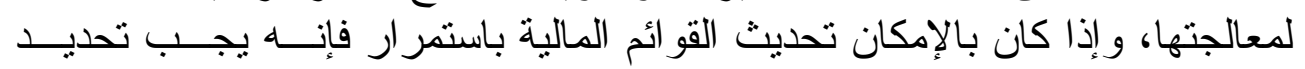

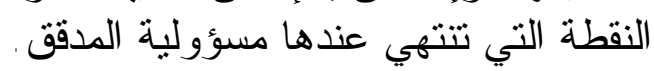

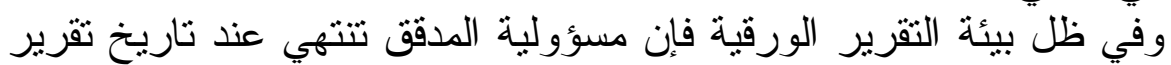

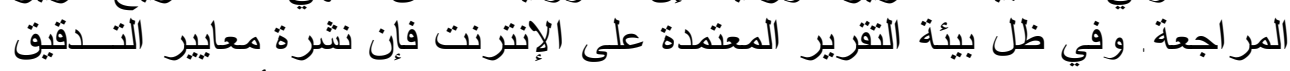

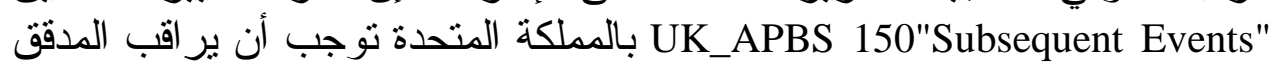

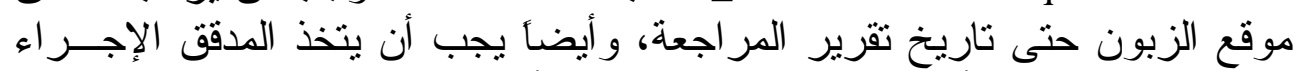

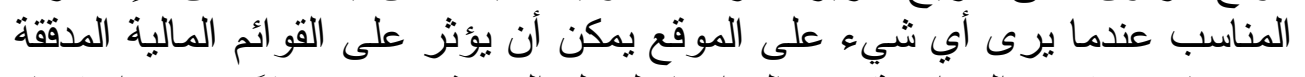

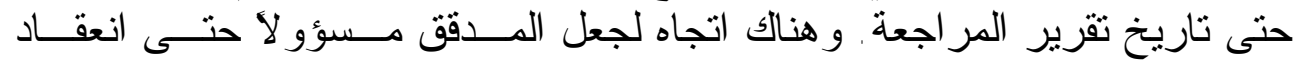

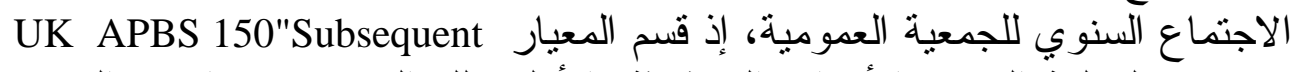

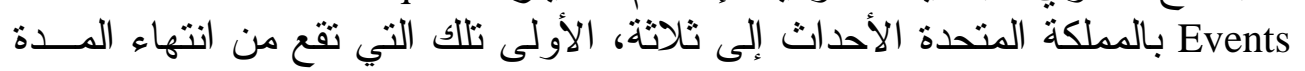

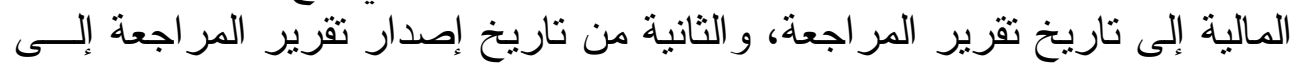


نشر القوائم المالية، والثالثة من إصدار القوائم المالية حتــى الاجتـــاع الـسنوي . (Debreceny \& Gray,1999)

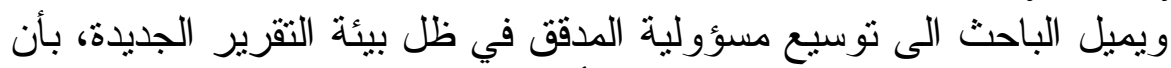

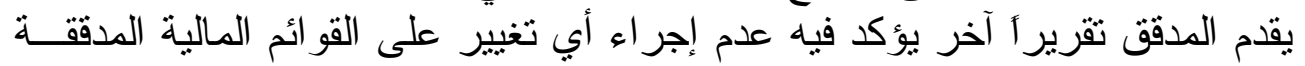

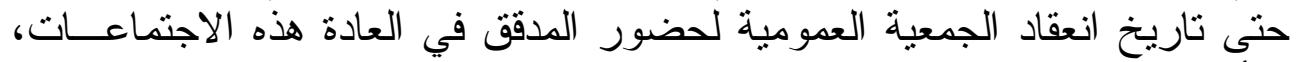

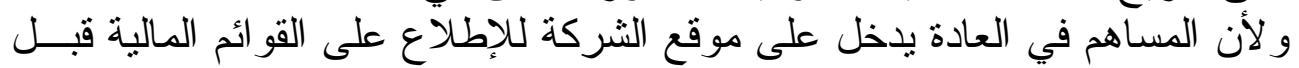

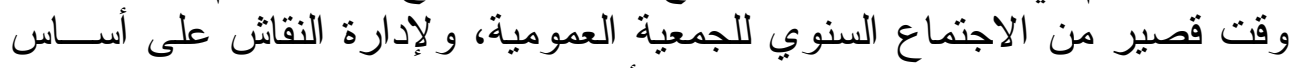

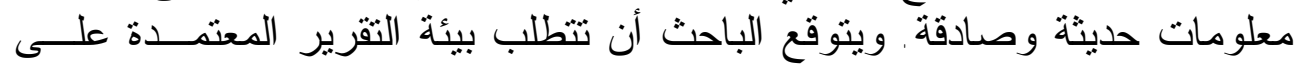

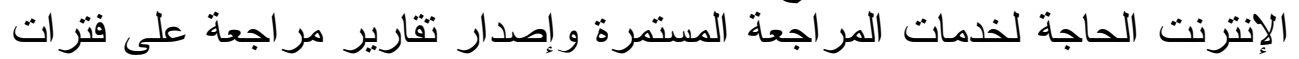

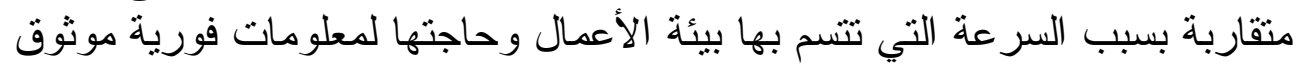
بها.

رابعاً - الخلاصة و التوصيات

مع ظهور الويب The World Wide Web ولغة التزميز Hoات Language (HTML)

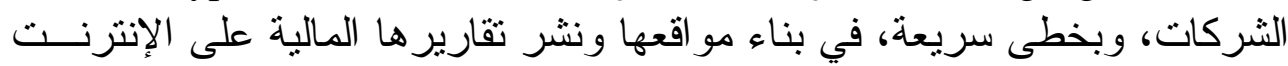

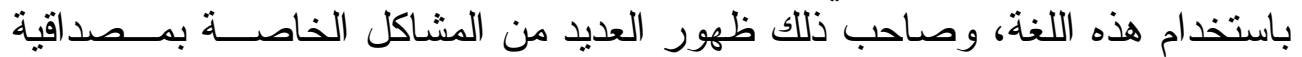

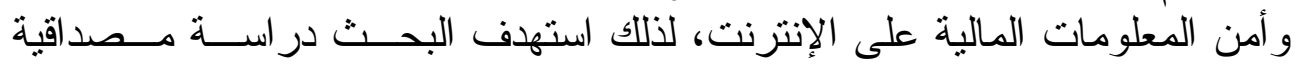

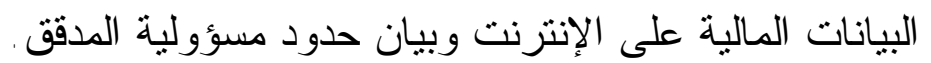

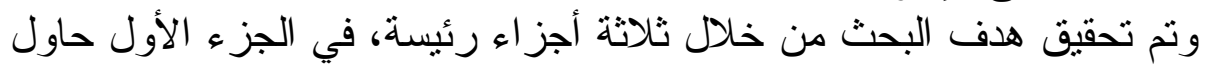

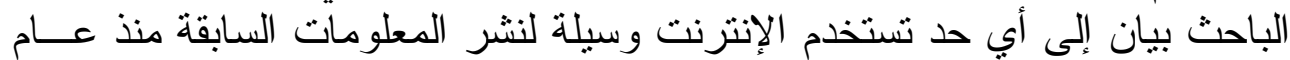

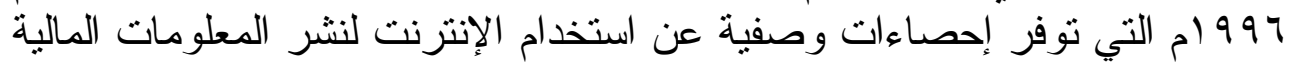

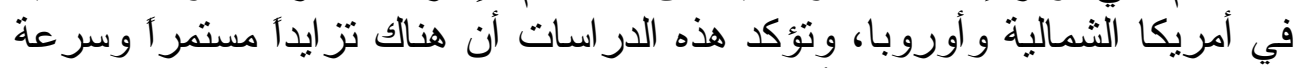

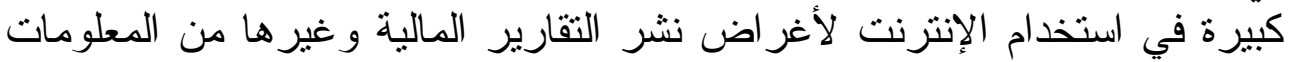

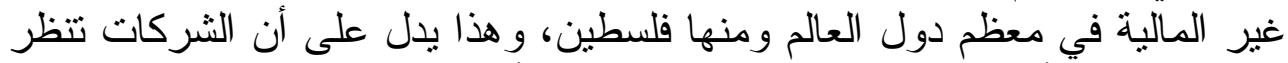

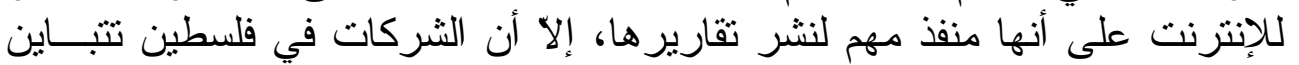

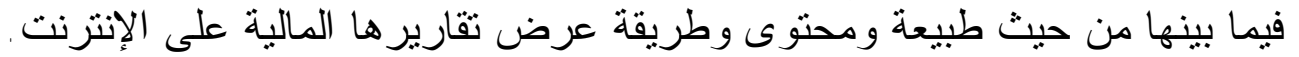

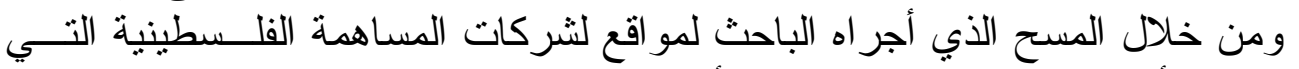

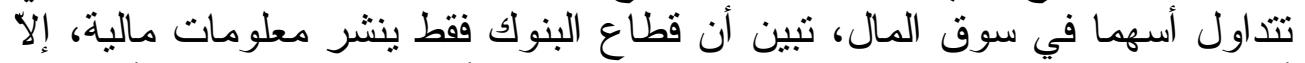

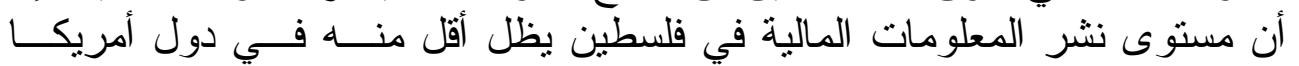
الثمالية وأوروبا.

وفي الجزء الثاني حاول الباحث بيان أهم الممارسات التي تحد من مصداقية الثالية

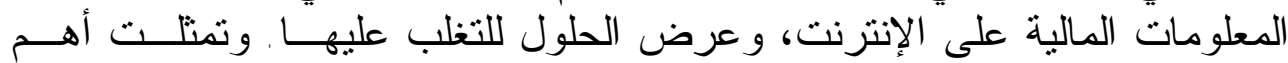
الممارسات في: (المعات 
الدكتور النعامي [4 - 1 [-

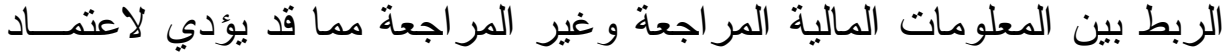

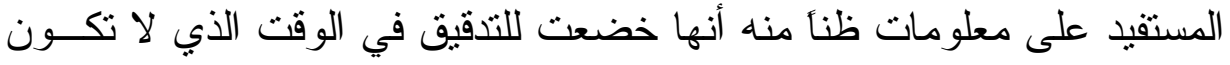
كذلك.

استخدام الوسائط المتعددة في عرض المعلومات مما وفر إمكانية كبيرة لتشويه

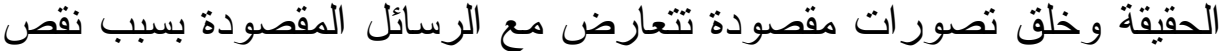

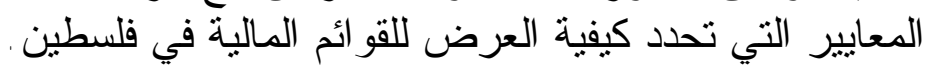

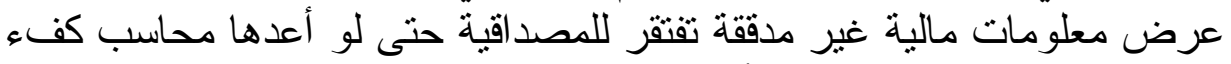

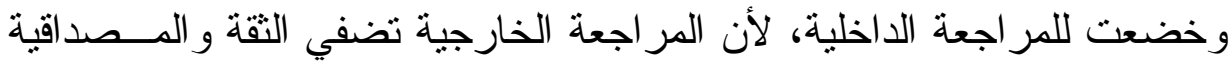
على أرقام القو ائم المالية.

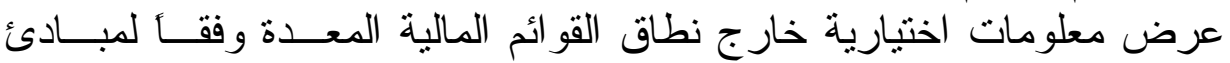

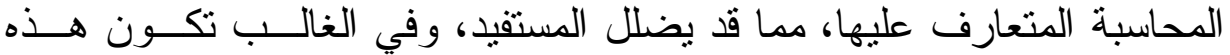
المعلومات غير صادقة ولئة ومتحيزة للإدارة.

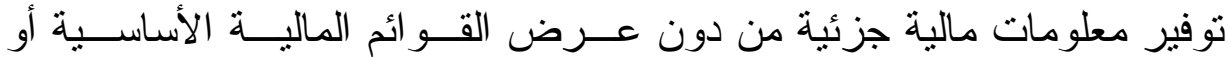

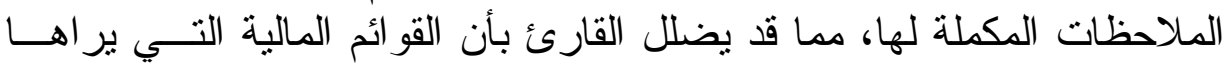

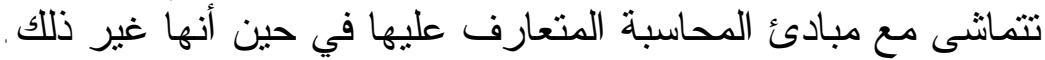

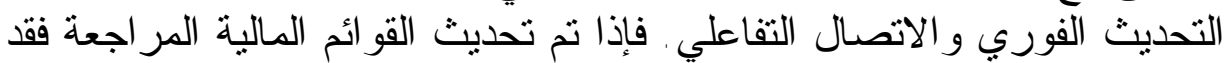

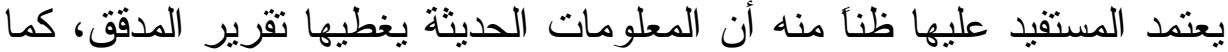
يسبب الاتصال التقاعلي مشاكل تتعلق بسرية المعلومات المبات و إمكانية تغيير ها.

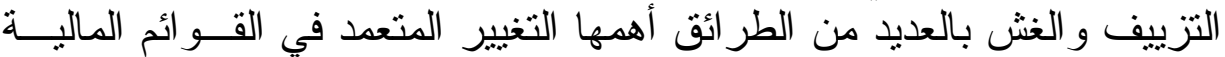

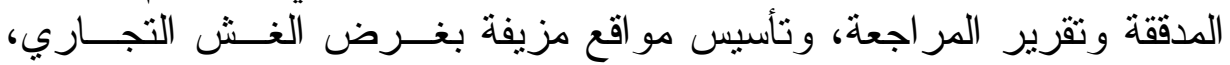
و واختراق وتدمير بعض المض المو اقع. ومن بين الحلول للتغلب على هذه الممارسات، وضع التع علامات إلى إلكترونية تخبر

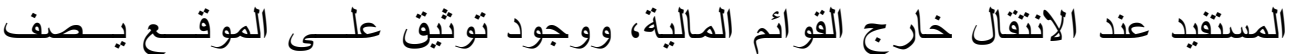

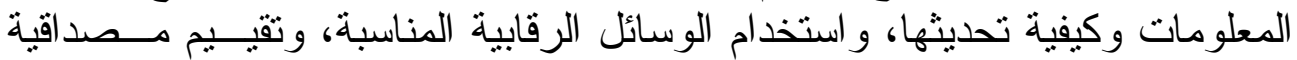

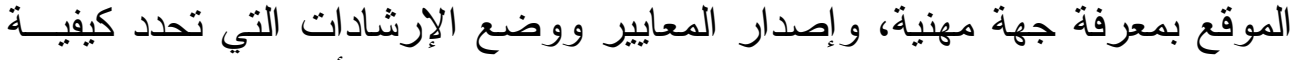

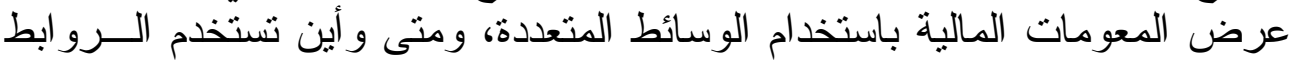
المتفاعلة، وكيفية التحقق من المعلومات الفية الفورية و التقارير المستمرة.

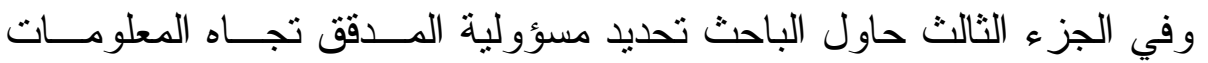

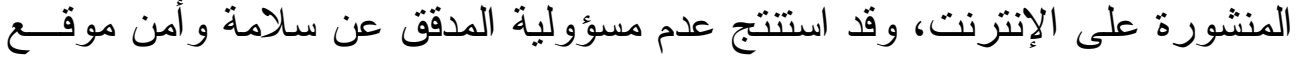

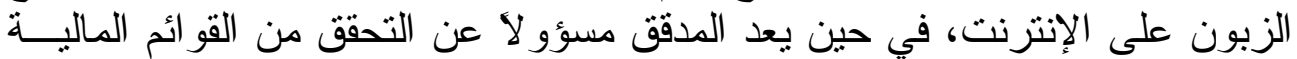

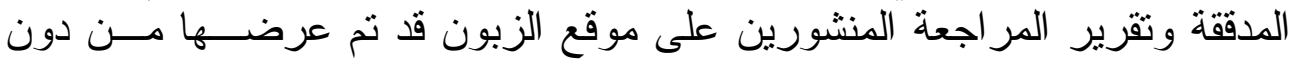

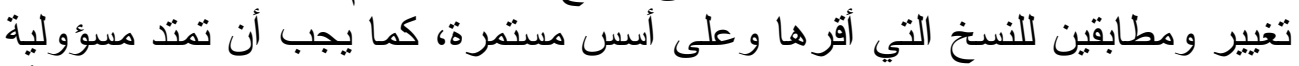

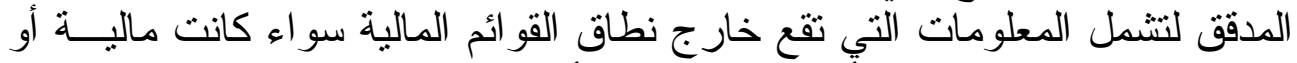

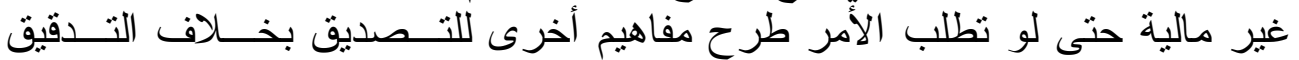

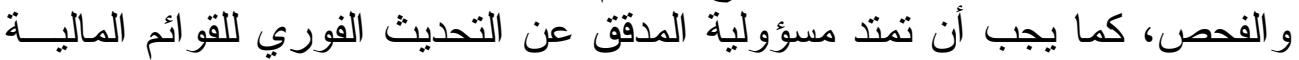
إلى تاريخ انعقاد الجمعية العمومية. 


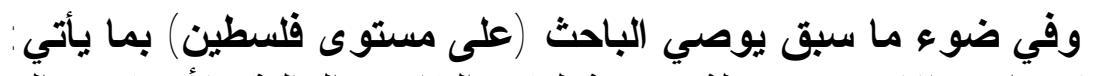

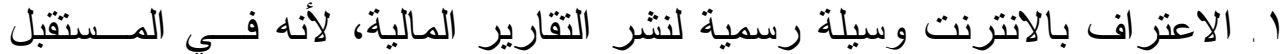

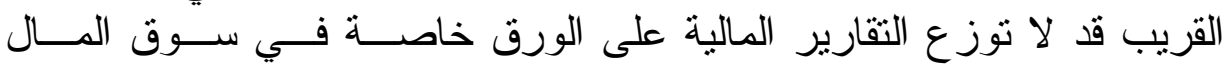
r. يجب أن تقبل المهنة المزيد من المسؤوليات وتوسع نطـــاق التقريــر ليــشمل

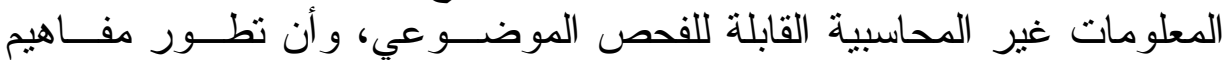

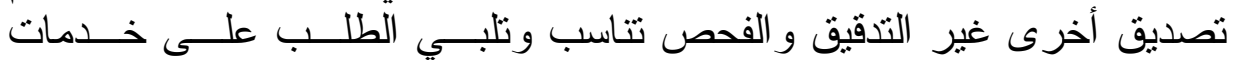

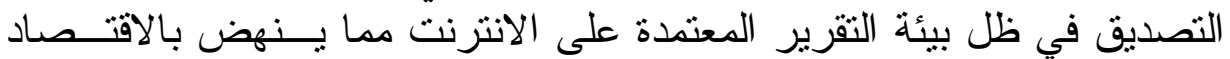

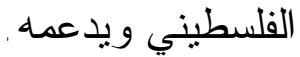

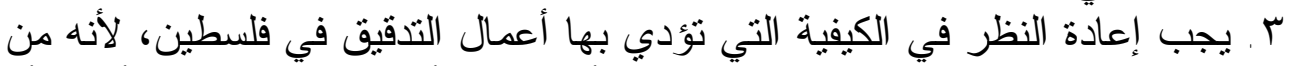

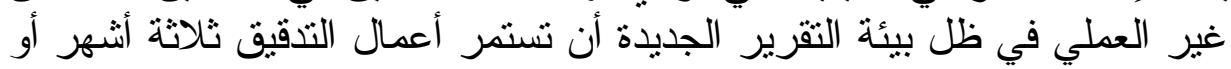

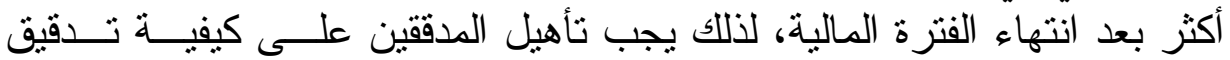
الأرقام الحية Live Numbers، و إصدار تقارير مر اجعة حركية تساير التحديث التعايث

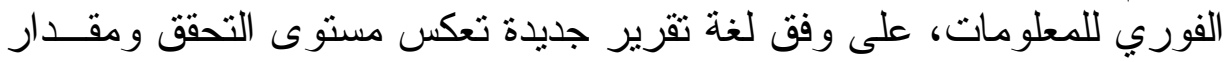

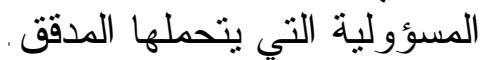
ع ـ إعداد دليل للسلوك المهني ومعايير تفصيلية على مستوى فلسطين توضح كيفية

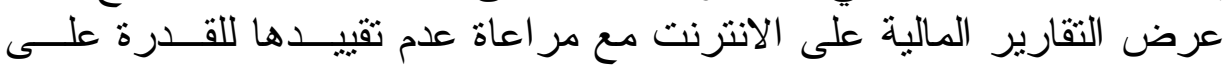

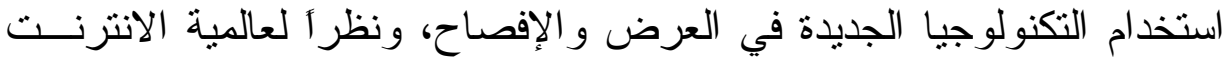

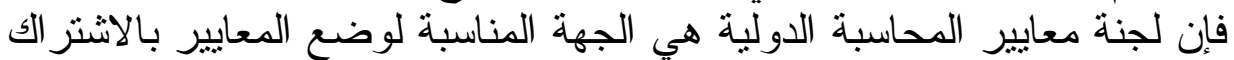

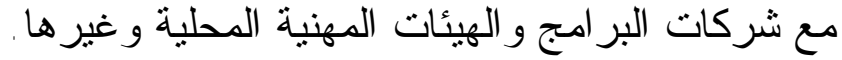

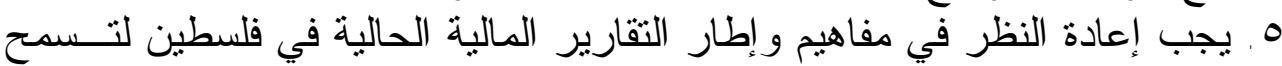

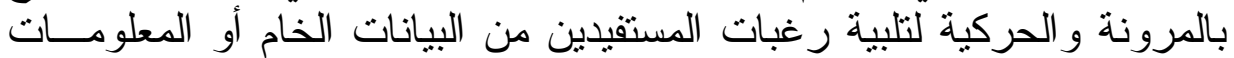

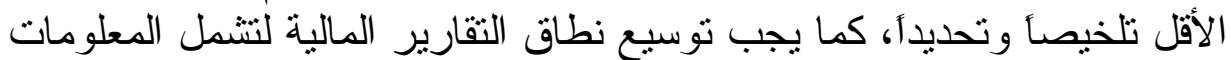

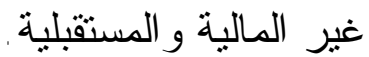

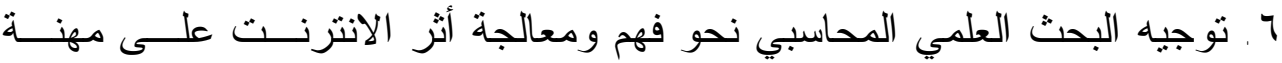

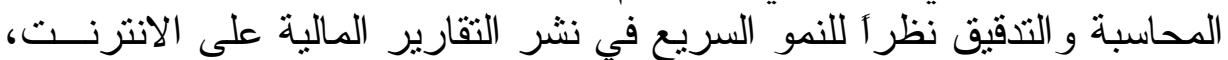

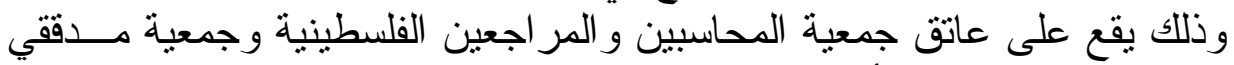
الحسابات الفلسطينية و أقسام المحاسبة في الجامعات و المعاهد الفلسطينية. 


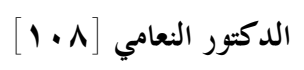

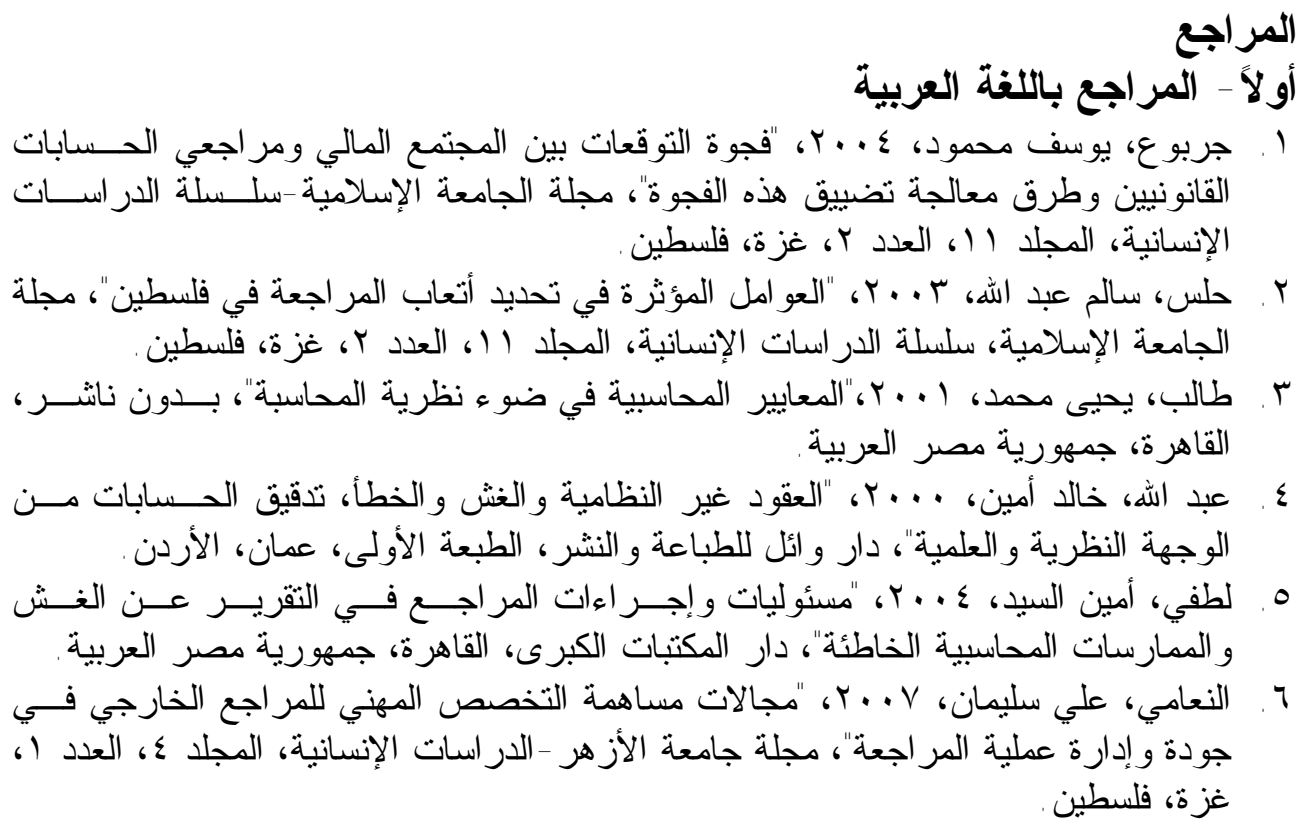

\section{ثانياً - المر اجع باللغة الأجنبية}

1.AICPA. "Improving Business Reporting-A Customer Focus (a.k.a. The Jenkins Report)."1999, available At (ttp://www.aicpa.org)12/15/2000.

2. Ashbaugh, H., K., Johnstone \& T. Warfield. "Corporate Reporting on the Internet." Accounting Horizons, September1999.

3. Baldwin, A.A. \& S. Williams. "The Future of Intelligent Internet Agents in European Financial Reporting. "The European Accounting Review, Vol.8, No. 2. 1999.

4. Bally, Larry P. "Miller GAAS GUIDE." Harcourt Brace \& company, 1998.

5. Craven, B.M. \& C.l. Marston. "Financial Repoting on the Internet By Leading UK Companies. "The European Accounting Review, Vol.8, No.2,1999.

6. Debreceny, R.,G.Gray, \& T.Barry. "Accounting Information in A Networked World Resource Discovery, Processing And Analysis. "Paper Presented At A.A.A Annual Meeting, New Orleans, 1998.

7.Deller, D., M. Stubenrath \& C. Weber. "A Survey on The Use of the Internet for Investor Relations In The USA, The UK And Germany. "The European Accounting Review, Vol.8,No.2,1999.

8.FASB."BRRP Electronic Distribution of Business Reporting Information."2000. available At (ttp://www.fasb.org)1/18/2001.

9. Gowthorpe, C. \& O. Amat. "External Reporting of Accounting And Financial Information Via the Internet in Spain." The European Accounting Review, Vol.8,No. 2,1999 .

10. Gray, G., \& R. Debreceny. "Corporate Reporting on the Internet."Paper Presented at the Asia - Pacific Conference on the International Accounting Issues, Bangkok, Nov. 1997.

11. Hedlin, P. "the Internet as A Vehicle for Investor Relations: The Swedish." The European Accounting Review, Vol.. 8,No.2,1999.

12. Hussey, R,J. Guliford \& A. Lymer, "UK Corporate Financial communications on the Internet. "Deliotte Touche Tohmatsu, 1999. 
13. Lymer, A. "The Use of the Internet in Company Reporting." Paper Presented At the British Accounting association Annual Conference Birminghem, 1997.

14. Lymer, A, \& A.Talberg. "Corporate Reporting and The Internet." Paper presented at the $20^{\text {th }}$ Annual Congress of the European Accounting Association, Graz, Austria, April 1997.

15. Lymer, A. \& others."Business Reporting on the Internet" IASC, November 1999.

16. Lymer, A. "the Internet and the Future of Corporate Reporting in Europe." The European Accounting Review, Vol.8, NO, 2, 1999.

17. Molero, L., M. Prado, \& F. Sevillano. "the Presentation of Financial Statement through the Internet." Paper presented at the $22^{\text {nd }}$ Annual Congress of the European Accounting Association, Bordeaux, France, 1999.

18. Peravick, S. \& J. W. Gillet. "Distributing Earnings Reports on the Internet." Management Accounting Vol.80, No. 4,1998.

19. Peravick, S. \& J. W. Gillet. "Financial Reporting on the World Wide Web." Management Accounting, Jul.1996.

20. Stvens, Michael G. "Financial Information is Flooding the Internet." The Practical Accounting Feb.1999.

21. Trites, Gerald D. "the Impact of technology on Financail and Business Reporting." CICA, 1999. 